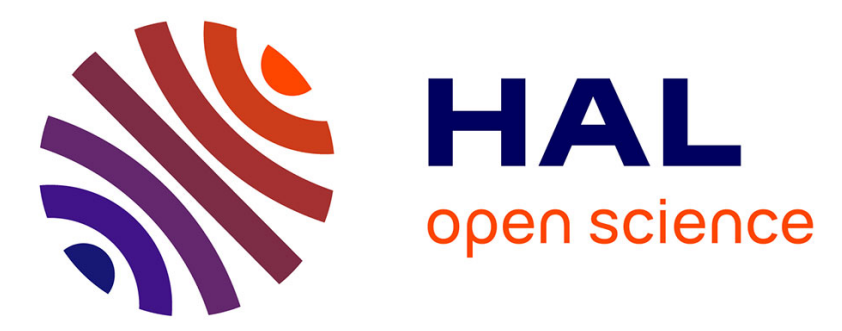

\title{
Role of STAT3 in Genesis and Progression of Human Malignant Gliomas
}

\author{
Zangbewende Guy Ouedraogo, Julian Biau, Jean-Louis Kemeny, Laurent \\ Morel, Pierre Verrelle, Emmanuel Chautard
}

\section{- To cite this version:}

Zangbewende Guy Ouedraogo, Julian Biau, Jean-Louis Kemeny, Laurent Morel, Pierre Verrelle, et al.. Role of STAT3 in Genesis and Progression of Human Malignant Gliomas. Molecular Neurobiology, 2017, 54 (8), pp.5780-5797. 10.1007/s12035-016-0103-0 . hal-01636877

\section{HAL Id: hal-01636877 https://hal.science/hal-01636877}

Submitted on 17 Nov 2017

HAL is a multi-disciplinary open access archive for the deposit and dissemination of scientific research documents, whether they are published or not. The documents may come from teaching and research institutions in France or abroad, or from public or private research centers.
L'archive ouverte pluridisciplinaire HAL, est destinée au dépôt et à la diffusion de documents scientifiques de niveau recherche, publiés ou non, émanant des établissements d'enseignement et de recherche français ou étrangers, des laboratoires publics ou privés. 


\title{
Role of STAT3 in genesis and progression of human malignant gliomas
}

Zangbéwendé Guy Ouédraogo ${ }^{1,2,5}$ (MD-PhD), Julian Biau ${ }^{1,2,4}$ (MD-MSc), Jean-Louis Kemeny $^{1,3}$ (MD-PhD), Laurent Morel $^{6}$ (PhD), Pierre Verrelle ${ }^{1,2,4}$ (MD-PhD) and Emmanuel Chautard $^{1,2}(\mathrm{PhD})$.

${ }^{1}$ Clermont Université, Université d'Auvergne, EA 7283, CREaT, BP 10448, F-63000 CLERMONT-FERRAND, FRANCE

${ }^{2}$ Centre Jean Perrin, Département de Radiothérapie, Laboratoire de Radio-Oncologie Expérimentale F-63000 CLERMONT-FERRAND, FRANCE

${ }^{3}$ CHU Clermont-Ferrand, Service d'Anatomopathologie, F-63003 CLERMONT-FERRAND, FRANCE

${ }^{4}$ Institut Curie, Département de Radiothérapie, 91405 Orsay, FRANCE

${ }^{5}$ Laboratoire de Pharmacologie, de Toxicologie et de Chimie Thérapeutique, Université de Ouagadougou, 03 BP 7021 OUAGADOUGOU 03, BURKINA FASO

${ }^{6}$ Clermont Université, Université Blaise-Pascal, GReD, UMR CNRS 6293, INSERM U1103, 24 Avenue des Landais BP80026, 63171 Aubière

63177 AUBIERE, FRANCE

Address correspondence to : Emmanuel Chautard, Centre Jean Perrin, Laboratoire de Radio-Oncologie Expérimentale, EA7283 CREaT - Université d'Auvergne, 58 rue Montalembert, Clermont Ferrand, 63011, France. Tel : +33.4.73.27.81.42; Fax : +33.4.73.27.81.25; E-mail : Emmanuel.chautard@Clermont.unicancer.fr

Funding: This work was supported by the Ligue Nationale Contre le Cancer (Comité du PuyDe-Dôme), by the Institut National du Cancer and by the Region Auvergne. ZG.O. was the recipient of a fellowship from the Ministère des Enseignements Secondaire et Supérieur, Burkina Faso.

\begin{abstract}
Signal Transducer and Activator of Transcription 3 (STAT3) is aberrantly activated in glioblastoma and has been identified as a relevant therapeutic target in this disease and many other human cancers. After two decades of intensive research, there is not yet any approved STAT3-based glioma therapy. In addition to the canonical activation by tyrosine 705 phosphorylation, concordant reports described a potential therapeutic relevance of other post-translational modifications including mainly serine 727 phosphorylation. Such reports reinforce the need to refine the strategy of targeting STAT3 in each concerned disease. This review focuses on the role of serine 727 and tyrosine 705 phosphorylation of STAT3 in glioma. It explores their contribution to glial cell transformation and to the mechanisms that make glioma escape to both immune control and standard treatment.
\end{abstract}

Keywords : STAT3, Glioma, Tyrosine 705, Serine 727 


\section{INTRODUCTION}

Glioma are the most frequent primary adult brain tumors. In 2016, the WHO published a new classification of glioma integrating both histological and biomolecular features [1]. They are classified by histological pattern as astrocytic and oligodendroglial tumors according to the World Health Organization (WHO) classification. The most of adults' glioma are infiltrative or diffuse tumors which make resection almost always incomplete. Diffuse glioma are categorized into low-grade glioma (WHO grade II), with slow growth, and high-grade or anaplastic glioma (WHO grades III and IV) that are fast-growing. Glioblastoma (GBM) is the most frequent and malignant type of glioma (grade IV), the most common primary tumors of the central nervous system. Primary GBMs arise de novo while secondary GBMs develop from grade II and III glioma. Primary and secondary GBMs are indistinguishable histologically, but they differ in their genetic and epigenetic profiles [2]. Isocitrate dehydrogenase 1 (IDH1) and less frequently IDH2 mutations are major molecular markers of secondary GBMs [3]. The first line setting of GBM patient treatment encompasses surgery followed by tumor bed irradiation and concomitant and then adjuvant chemotherapy with temozolomide [4]. Despite such a complex therapy, recurrence is unavoidable, due to GBM cell radiochemoresistance [5] and the median survival is nowadays around 14 months. Management of GBM patients at recurrent disease state is not unanimously codified because of an enhanced aggressiveness [6]. Glioma are one of human cancers in which existence of cancer-initiating cells also called cancer stem-like cells, has been established [7, 8]. Cancer stem cells have self-renewal and tumorigenic capacities and reproduce some but not all stem cells behaviors [9]. Genetic studies using murine glioma models revealed that glioma stemlike cells may arise from neural stem cells that are localized mainly at the ependymal surface of the ventricles [10]. Furthermore, it has been reported that GBM in close proximity to the ependymal surface of the ventricles convey a worse prognosis [11, 12]. Therefore, glioma stem-like cells and their specific features are thought to be involved in glioma genesis, recurrence and aggressiveness.

Several pathways have been reported as involved in the pathogenesis of GBM [13]. Some of them have been reported as prognostic markers or therapeutic targets. Signal Transducer and Activator of Transcription 3 (STAT3) has been identified as a therapeutic target [14] in glioma because (i) several signalling pathways altered in glioma converge to STAT3 and (ii) it is involved in several hallmarks of glioma aggressiveness, through modulation of genes notably implicated in cell proliferation, growth, apoptosis, migration, invasion and neoangiogenesis. STAT3 belongs to a protein family encompassing seven members sharing a common structure but largely differing in their functions. It is well established that STAT3 is an intracellular cell signalling protein activated by canonical phosphorylation [15] on its tyrosine 705 residue (pSTAT3-Y705), which induces its transfer to the nucleus for target gene regulation [16-18]. In addition to glioma, many other human cancers display activated STAT3. Therefore, studying the role STAT3 in cancer provided rational for design of STAT3 inhibitors to be used as anticancer targeted therapy [19, 20]. However such inhibitors have not yet been approved for treatment of glioma patients because of toxicity or inefficiency. This strengthens the need to refine the strategy of targeting STAT3 in glioma. Furthermore, recent concordant evidences attributed biological functions to posttranslational STAT3 modifications other than Y705 phosphorylation, including lysine methylation [21] and acetylation [22-24] as well as serine 727 phosphorylation (pSTAT3S727). All these modifications cooperate with or act independently from the canonical pSTAT3-Y705 in regulating STAT3 activity [25-27]. Existence of such post-translational STAT3 modifications should be taken in account in STAT3 based drug designing. However, investigators did not always assess STAT3 activation through detection of all activated forms, including mainly pSTAT3-Y705 and pSTAT3-S727 together. Understanding the fine 
regulation of STAT3 in glioma and the role of each of its post-translational modifications in the disease aggressiveness may help improve the therapeutic targeting of STAT3.

After a general description of STAT3 signalling, this review focuses on S727 and Y705 phosphorylation of STAT3 and their involvement in the biological processes that lead to glial cell transformation as well as tumor growth and escape to both immune control and standard treatment. 


\section{STAT3 IN THE STAT PROTEIN FAMILY}

The STAT proteins constitute a family of signal transducers and transcriptional regulators. This family encompasses STAT1, 2, 3, 4, 5A, 5B and 6 [28]. Each of them is encoded by a unique different gene. The STAT proteins are characterized by a common structure (Figure 1) that typically consists of an N-terminal domain, a coiled-coil domain, a DNA-binding domain, a linker, an SH2 domain, and a transactivation (TA) domain [29]. The TA domain contains tyrosine and serine phosphorylation sites that are involved in STAT activation. There are truncated isoforms which are generated by alternative mRNA splicing of the single gene transcript of STAT1 [30], STAT3 [31-33], STAT4 [34], STAT5A [35], STAT5B [36] and STAT6 [37]. In addition, isoforms resulting from proteolytic cleavage of STAT3 [38], STAT5A [39, 40], STAT5B and STAT6 [41] have been identified. Most truncated isoforms act as dominant-negative of the corresponding full-length proteins [38, 42, 43]. STAT2, 4 and 6 are mainly involved in immune system regulation whereas STAT1, 3 and 5 play immunological and many other biological functions. STAT3 and STAT5 are hyper-activated in many human cancers where they contribute to cell transformation [44-46] and to survival and proliferation of transformed cells [47]. Therefore, they have been identified as relevant targets for the development of anticancer therapies [44, 48].

The gene encoding STAT3 is located in the human 17q21.31 genomic region and is expressed in several cell types [49]. Alternative mRNA splicing and proteolytic cleavage give rise to STAT3 $\alpha$ (full-length) isoform consisting in 770 aminoacids and to STAT3 $\beta$, a 722 aminoacids dominant-negative variant [38]. STAT3 expression is crucial for the embryogenesis, attested by mouse models, since homozygous knock-out of STAT3 resulted in lethal embryonic degeneration at day 6.5-7.5 [50]. Consistently, there is no reported homozygous inactivation of STAT3 in human, strengthening the requirement of STAT3 in embryonic development.

Heterozygous inactivating mutations by transition, transversion or punctual deletions in STAT3, mainly located in the DNA-binding domain and the SH2 domain, have been associated to Autosomal Dominant Hyper-Immunoglobulin E Syndrome (AD-HIES) previously called Job's syndrome [51-55]. AD-HIES patients have an elevated IgE level in serum, with an immune deficiency that involves lymphocytes, mainly Th17, Tfh, memory B cells and TCD8+ cells. They also have a susceptibility to develop B type lymphomas and are exposed to diverse infectious diseases.

Furthermore, gain-of-function mutations in the DNA binding domain or the dimerization domain of STAT3 have been associated to auto-immune disorders that confirmed the involvement of STAT3 in the immune system functional maturation [56, 57]. Functional activation of STAT3 due to punctual mutations in SH2 domain has been observed in chronic lymphoproliferative disorders of NK cells and in T-cell large granular lymphocyte leukemia $[58,59]$. 


\section{GENERAL DESCRIPTION OF STAT3 PATHWAY SIGNALLING}

The pool of STAT3 in cells is submitted to a fine regulation consisting in several mechanisms. This includes a synthesis-degradation cycle, controlled by proteasomedependent pathways, that regulates total STAT3 availability [60, 61]. Another mechanism is an activation-inactivation cycle that makes STAT3 activation transient as a rule. Phosphorylation/dephosphorylation is the best known STAT3 pathway modulating mechanism. This is due to cooperation between finely regulated enzymes which are tyrosine kinases, serine/threonine kinases and many phosphatases [62]. Phosphorylation is prior to nuclear translocation and subsequent gene expression modulation. The main conserved signalling pathways driving STAT3 phosphorylation are summarized in Figure 2.

\section{From STAT3-Y705 phosphorylation to dimerization and transcription activation}

At its discovery in 1994, STAT3 was described as an acute-phase response factor activated in response to cytokines that induce signal through the gp130 transmembrane protein. Those cytokines include interleukin-6 (IL-6), leukemia inhibitory factor (LIF), oncostatin M (OSM), and the ciliary neurotrophic factor (CNTF) [63, 64]. Upon phosphorylation of gp130, STAT3 is recruited to the gp130 cytoplasmic region by interaction with its SH2 domain. To phosphorylate the Y705 residue of STAT3, the receptor complex recruits a member of Janus Kinase (JAK) family of cytoplasmic kinases including JAK1, JAK2, JAK3 and TYK2. Among them, JAK2 is the main STAT3-Y705 activator (Figure 2).

Plasma membrane receptors carrying an intrinsic intracellular protein-tyrosine kinase activity may also trigger STAT3 phosphorylation of the Y705 residue. These include growth factor receptors such as the EGFR [65, 66] and PDGFR [67].

Besides intrinsic and extrinsic activity involving cell-surface cytokine receptors, pSTAT3-Y705 can be induced directly by some cytoplasmic kinases including the Src family [68], Bone Marrow X-linked (BMX [69, 70]) and the Bcr-Abl fusion protein [71, 72].

Two pSTAT3-Y705 associate to form active dimers capable of translocating to the nucleus. Therein, they interact with specific response element consisting in $\mathrm{TTN}_{4-5} \mathrm{AA}$ consensus DNA sequences called Interferon Gamma-activated sequences (GAS). They therefore induce transcription of specific target genes [16, 17] (Figure 3).

\section{Serine 727 phosphorylation and other post-translational modifications of STAT3}

In addition to Y705 phosphorylation, STAT3 is also activated by serine 727 phosphorylation. The functions and the kinases responsible of S727 phosphorylation of STAT3 have been discussed during the last 2 decades [73-75]. S727 phosphorylation is achieved by serine-threonine kinases that are members of the Protein Kinase C (PKC) family such as PKC- $\delta$ [76], PKC- $\varepsilon$ [77-79]. Cyclin-dependent kinase 5 was recently shown to interact and phosphorylate STAT3-S727 [80]. Other kinases downstream the MAP Kinase pathway [73, 74, 81] and the NOTCH pathway [25] have also been reported as involved in STAT3-S727 phosphorylation (Figure 2).

Recent studies provided evidence that the biological function and the regulation of pSTAT3-S727 depend on cell type and cell-differentiation state [26, 27, 82, 83]. Considering together the published data, it becomes clear that STAT3 plays a critical role in the control of many cellular processes (Figure 3). However the contribution of each of pSTAT3-Y705 and pSTAT3-S727 in those processes remains unclear because authors did not use methods that allow such distinguishing. In the light of the current knowledge, one can hypothesize that some genes are preferentially regulated by only one or both pSTAT3-Y705 and pSTAT3S727. In case of involvement of both phosphorylations, their action could be consistent or not. For instance, results reported by $\mathrm{Xu}$ et al. provided evidence that knockdown of PKCE attenuates pSTAT3-S727 and expression of Bcl-XL but not that of Bcl-2 which is another 
STAT3 downstream target. The authors hypothesized that knockdown of PKC $\varepsilon$ may influence signalling pathways that may compensate each other in regulating Bcl2 expression [79]. We further speculate, because pSTAT3-Y705 was unaffected by PKC $\varepsilon$ inhibition, that it may have maintained $\mathrm{Bcl}-2$ expression.

In addition to phosphorylation, concordant evidences attributed biological functions to other post-translational modifications of STAT3 including lysine methylation [21] and acetylation [22]. Such modifications require further investigation to decipher their role in the STAT3 cascade.

\section{STAT3 pathway down-regulation by tyrosine phosphatase activity}

The identified phosphatases involved in the dephosphorylation of pSTAT3-Y705 belong to a family of receptor-type phosphatases and to a group of non-receptor (intracellular) protein-tyrosine phosphatases. The category of receptor-like phosphatases includes mainly the Receptor-type tyrosine-protein phosphatase delta (PTPRD) [84, 85] and the Receptor-type tyrosine-protein phosphatase O (PTPRO) [86] that are enzymatic transmembrane proteins. The inhibiting pSTAT3-Y705 intracellular phosphatases are members of the Protein-tyrosine phosphatase non-receptor (PTPN) family including PTPN1 (or PTP1B) [87] , PTPN2 (or TCPTP) [88, 89] , PTPN6 (or SHP1) [90, 91] , PTPN9 (or PTPMeg2) [92, 93], PTPN11 (or SHP2) [94] and PTPN12 [95].

It was reported that pSTAT3-S727 activates TC45, a nuclear PTPN2 isoform to dephosphorylate pSTAT3-Y705 [96]. Therefore, TC45, may provide an explanation to a kind of a STAT3 autoregulation system described in early study of STAT3 showing that pSTAT3S727 negatively regulates pSTAT3-Y705 [73]. More recent investigations demonstrated that PASD1 protein competed with TC45 to associate with STAT3, blocking thus TC45-mediated dephosphorylation of STAT3. PADS1 serves therefore as a critical nuclear positive regulator of pSTAT3-Y705 [97].

\section{STAT3 pathway down-regulation by serine/threonine phosphatase activity}

Besides protein-tyrosine phosphatases, STAT3 dephosphorylation also involves protein serine/threonine phosphatases, mainly the Phosphoprotein phosphatase 2A (PP2A) [62, 98, 99]. Activity of such phosphatases on STAT3 is regulated by other STAT3 interacting proteins like the STAT3-Interacting Protein As a Repressor (SIPAR) that promotes dephosphorylation of pSTAT3-Y705 [100] and like 14-3-3ל, a protein that protects pSTAT3S727 from dephosphorylation by PP2A [99]. It has also been reported that a non-coding long RNA called Inc-DC interacts with STAT3 in dendritic cells and prevents fixation of SHP1 protein-tyrosine phosphatase [101].

\section{Other mechanisms modulating STAT3 pathway}

The fine regulation of STAT3 activity also involves the Protein Inhibitor of Activated STAT3 (PIAS3) that is an E3 SUMO-protein ligase [102, 103] that directly blocks activated STAT3 [102]. It moreover includes modulation of STAT3 upstream kinases such as the inhibition exerted by the Suppressor Of Cytokine Signalling (SOCS) on JAK protein family [104]. Lately, Lee et al. described that the endogenous transmembrane protein upstream-ofmTORC2 (UT2) interacts directly with gp130 and inhibits phosphorylation of STAT3Y705[105].

STAT3 is also submitted to a cytokine-induced acetylation and deacetylation process mediated on its $\mathrm{SH} 2$ domain lysine K685 respectively by p300 and type I HDAC family members [24]. K685 acetylation induces stable dimer formation required for cytokinestimulated DNA binding and gene transcription regulation. K685 acetylation is also critical for functional regulation of STAT3 lacking Y705 phosphorylation [106]. Acetylation of the 
STAT3 Coiled-coil domain on the K49 and K87 lysines has been reported. These modifications are also controlled by p300 and type I HDAC family members. However, functional analysis showed that unlike K685 acetylation, they are not involved in STAT3 dimerization and translocation to the nucleus, but they are required for IL-6-induced gene transcription [23].

Activated STAT3 is also regulated by methylation on K140 by the histone methyltransferase SET9 and by demethylation mediated by LSD1 [21]. K140 methylation of STAT3 is a negative regulator of transcription activation by promoter bound STAT3. Furthermore, phosphorylated or unphosphorylated STAT3 [107] physically interact with various other transcription factors thus contributing to their functional regulation. These include STAT1 [108], the Sp1 transcription factor [109], PPAR- $\gamma$ [110], Smad1 [111], the androgen receptor [112], Nuclear Factor $\kappa B(N F-\kappa B)$ [113] and c-Jun [114]. Since the STAT3 pathway regulation is complex, a precise description of activated patterns and causal mechanisms in each concerned disease should be helpful in designing STAT3-based therapy. 


\section{THE MECHANISMS LEADING TO STAT3 ACTIVATION IN HUMAN GLIOMA CELLS}

\section{Activation of protein tyrosine kinases}

There is not any identified gain-of-function mutation of human STAT3 in glioma; the constitutive activation of STAT3 in this disease is therefore due to an aberrant signal from upstream regulators. This includes, on one hand, any gain-of-function mutation or increase in activation of an upstream activator, and, on the other hand, any loss-of-function mutation or any decrease in activation of an upstream repressor. The first group involves mainly alterations in the EGFR signalling pathway and those in the IL-6 signalling axis. Both pathways are induced by receptor-associated tyrosine kinase activities. Gene amplification and/or rearrangements that result in the EGFRvIII truncated variant of EGFR, or the EGFRSEPT 14 fusion mutant of EGFR, induce an aberrant, excessive signal leading to a hyperactive pSTAT3-Y705 [115, 116]. Insulin-like growth factor binding protein 2 (IGFBP2) augments the nuclear accumulation of EGFR to potentiate STAT3 transactivation activities, via activation of the nuclear EGFR signalling pathway [117].

In addition to or independently of EGFR activation, IL-6 participates in complex genetic and epigenetic regulatory circuits that orchestrate STAT3 constitutive activation in glioma [118]. We have reported IL-6 overexpression in GBM patients and cell lines [119, 120]. IL-6 induces STAT3 activation by a signal transduced through an hexameric transmembrane receptor complex that implicates the IL-6R $\alpha$ (gp80) and the gp130 subunits and that is shared with receptors of other cytokines such as IL-11, LIF, CT-1, CTNF, OSM and CLC [121]. Among them, OSM plays, as IL-6, a critical role in glioma [122, 123]. OSM mainly contributes to aggressiveness of mesenchymal subtype of glioma [124]. OSM receptor (OSMR) was reported to form a complex with EGFRvIII. This complex activates STAT3 and upregulates OSMR expression. The result is a feed-forward signalling mechanism that drives oncogenesis [125]. IL-6 induced STAT3 activation was usually assessed by monitoring pSTAT3-Y705 [126]. But Liu et al. reported a dose-dependent increasing accumulation of pSTAT3-S727 in T98G and U251 human GBM cell lines treated by various concentrations of IL-6 [127]. In that assay, variation of pSTAT3-Y705 has not been evidenced. To our knowledge, such demonstration has not yet been reproduced. We used IL-6 blocking antibodies to challenge GBM cells and it resulted in a decrease in pSTAT3-Y705 while pSTAT3-S727 remained stable (unpublished data). Apart from gp130 signalling chemokines, IL-22, hypothetically secreted by stromal cells was reported to activate pSTAT3-Y705 in glioma cells [128]. Moreover, it has been shown that STAT3 activation increased transactivation of VEGF promoter and VEGF secretion by GBM cells [129, 130]. In addition to those pathways, pSTAT3-Y705 can be induced through signal induced by many other cytokines or growth factor receptors such as PDGFR, depending on cell type or experimental conditions [131].

Besides its induction by receptor-associated tyrosine kinase activity, activation of STAT3 in glioma can also be triggered by non-receptor tyrosine kinases. This implicates intracellular kinases such as BMX which is expressed by some GBM stem-like cell subpopulation [132]. Since knocking down BMX impaired pSTAT3-Y705 accumulation, it has been described as an upstream activator of STAT3 in GBM stem-like cells.

\section{Activation of protein serine/threonine kinases}

Serine/threonine kinases are intracellular proteins that can mediate STAT3 activation by phosphorylating its serine 727 residue. The serine/threonine kinase protein kinase C epsilon (PKC $\varepsilon$ ) is overexpressed in human anaplastic astrocytoma, GBM and gliosarcoma and is associated to a worse disease prognosis [133]. This overexpression of PKCE has been 
shown to take part in the constitutive activation of STAT3 through serine 727 phosphorylation in several human glioma cell lines [77, 79].

The NOTCH pathway has been implicated in STAT3 activation since it has been shown that NOTCH signalling stimulation by Delta-like 4 (Dll4) and Jagged 1 (Jag1) NOTCH ligands promotes human embryonic stem cell survival through STAT3 serine 727 phosphorylation [134]. This NOTCH-mediated effect on normal stem cell fate can be blocked by the NOTCH pathway inhibitor DAPT, a gamma-secretase inhibitor that impairs activating cleavage of NOTCH by Presenilin 1. Moreover, the preponderant role of NOTCH in activating STAT3-S727 in glioma became evident when Fan et al. demonstrated that blocking activated NOTCH pathway in GBM stem-like cells by Gamma-Secretase Inhibitor 18 (GSI18), reversed accumulation of pSTAT3-S727 and furthermore selectively impeded cell proliferation [25]. Those findings suggest that there is a regulation loop involving activated STAT3 and NOTCH signalling because NOTCH pathway regulates pSTAT3-S727 and pSTAT3-Y705 participates with NFאB in regulating activated NOTCH signalling in GBM stem-like cells [135]. More studies should help decipher this regulatory loop in GBM stemlike cells.

\section{Deficiency in upstream repression of STAT3}

Apart from an increased activity of an upstream activator, any loss-of-function mutation or any decrease in activation of an upstream repressor may explain the constitutive activation of STAT3 in glioma. This second group of deregulating mechanisms involves the PIAS3, the SOCS, and PTPRD.

Concordantly with pSTAT3-Y705 and pSTAT3-S727 overexpression, the PIAS3 is less expressed in GBM in comparison with non-neoplastic brain tissue [136]. Furthermore, inhibition of PIAS3 in U87-MG human glioma cell line by RNA interference boosted cell proliferation despite no or little change in the level of phosphorylated STAT3. Conversely, overexpression of PIAS3 in U251-MG human glioma cell line dumped OSM-enhanced expression of the STAT3 targeted genes Survivin, Bcl-xL as well as SOCS3 and resulted in $80 \%$ slow-down of cell proliferation [136].

The SOCS protein family includes cytokine inducible signal transducers that encompass several members involved in negatively regulating cytokine and growth factorinduced signal [137]. Among them, SOCS3 is not only a STAT3 target-gene but also an upstream repressor of STAT3 via its inhibitory action on JAK kinases [138]. Thus, SOCS3 functions in a negative feedback loop to regulate STAT3 activity. GBM tumors and cell lines overexpress $S O C S 3$ whereas they repress $S O C S 1[136,139,140]$. This aberrant expression of SOCS3, concomitant with a constitutive activation of STAT3, suggests that SOCS3 is induced by STAT3 pathway [140] even if SOCS3 might fail in inhibiting STAT3 in GBM. Further study should help understand the link between the constitutive silencing of SOCS1 and activated STAT3.

PTPRD belongs to a family of protein-tyrosine phosphatases which are involved in the regulation of many normal and cancer cell processes such as adhesion, proliferation and migration, through the regulation of multiple cell-signalling pathways [85]. PTPRD function is frequently inactivated by genetic and epigenetic alterations in GBM as well as in other cancers, and is associated to a worse patient prognosis [141, 142]. Functional analysis in mice, recently published by Ortiz et al. showed that loss of heterozygoty of PTPRD resulted in accumulation of pSTAT3-Y705 and cooperated with $C D K N 2 A / p 16^{I N 4 K A}$ to promote glioma tumorigenesis [143]. 


\section{Other STAT3 activating mechanisms}

Apart from deregulation of upstream regulators, other factors cooperate in inducing hyperactivity of STAT3 in glioma. Some of them have been identified but more studies are required to well characterize the mechanisms of their action. This is the case of the mutation in the GDNF Family Receptor Alpha 4 (GFRA4) gene exon 2 that induces mislocated weaklyinteracting GFRA4-persephin (PSPN) complexes. These complexes aberrantly dissociate from the RET proto-oncogene product (RET) at the plasma membrane and relocate to the endoplasmic reticulum [144]. Moreover, GFRA4 silencing or artificial redirection of GFRA4 to the plasma membrane reduced pSTAT3-Y705 and resulted in slowed glioma cell proliferation. 


\section{EVIDENCE AND PROGNOSTIC VALUE OF STAT3 ACTIVATION IN GLIOMA SPECIMENS}

\section{Phosphorylation of STAT3-Y705}

Phosphorylated STAT3 has been detected by immunohistochemistry assays performed on frozen or paraffin-embedded glial tumour sections and by immunoblotting of tumour tissue samples. The early studies reported positive detection of pSTAT3-Y705 in a variable proportion of glioma of the studied cohorts [116, 145-148]. This variability might be due to the cohort size and to the limits of sensitivity and specificity of the diagnosis and of the detection methods. Moreover, comparison of the published results should consider that the cut-off point of positive detection was different. The detected pSTAT3-Y705 was located in the nucleus of a variable number of glial tumour cells or tumour-associated lymphocytes or vascular endothelial cells $[116,146,148]$. Normal brain tissue was negative for pSTAT3Y705 staining except in one over 5 specimens reported by Lo et al. [116]. Considering the group of specimens in which the section showed more than 20\% pSTAT3-Y705 positively stained cells, Lo et al. found a positive correlation of pSTAT3-Y705 and glioma grade. However, in a cohort of 111 GBM (WHO grade IV glioma) cases and 25 WHO grade III gliomas, Birner et al. did not find any correlation with the disease grade among cases that showed more than 5\% positive cells [149]. Using other methods such as electrophoretic mobility shift assay and western blotting, greater proportions of pSTAT3-Y705 expressing tumours or higher levels of pSTAT3-Y705 have been positively correlated to glioma tumour grade $[136,150]$.

\section{Constitutive phosphorylation of STAT3-S727}

The detection of serine pSTAT3-S727 in U87-MG and U373-MG glioma cell lines has been achieved by western blot showing STAT3 inhibition that accompanied cell death induced by telomere 3' overhang-specific DNA oligonucleotides [151]. The first description of serine pSTAT3-S727 in glioma tissues has been reported by Brantley et al. [136]. Two years later, this constitutive activation of STAT3-S727 has been confirmed in patient- and cell line-derived GBM stem(-like) cells [25, 27]. This study of Villalva et al. evidenced that STAT3 was activated in GBM stem-like cells mainly through pSTAT3-S727. Moreover, disruption of STAT3 activity impaired proliferation and neurosphere formation. Recently pSTAT3-S727 has been described by immunohistochemistry in 70.5\% of 88 GBM cases [152]. Even though pSTAT3-S727 was found in the cytoplasm, the main subcellular location was the nucleus of the neoplastic cells and some vascular endothelial cells. Normal brain tissue did not show any expression of pSTAT3-S727. Moreover, this study of Lin et al evidenced a statistically significant association of pSTAT3-S727 and pSTAT3-Y705 [152]. In a cohort of 30 GBM clinical specimens and a panel of 15 GBM cell lines, we showed that pSTAT3-S727 is present in all studied human malignant glioma cell lines and all the examined GBM specimens [153]. However, pSTAT3-Y705 was not detected in some GBM cell lines or specimens and was moreover restricted to a variable number of GBM cells in the positive clinical samples. These results are consistent with an involvement of pSTAT3-S727 in the process of oncogenesis as a driving mechanism as suggested for mouse hepatocarcinomas [82] or as a consequence of cell transformation. Analysis of these two phosphorylations in relation with tumor grade might help to confirm or infirm this hypothesis.

\section{STAT3 AND PROGNOSIS}

Many studies have examined the prognostic value of STAT3 expression and activation in glioma. Early studies of the signalling pathways activated downstream EGFR, including MAPK, Akt and STAT3, established that pSTAT3-Y705 is correlated to the presence of the 
EGFRVIII muted variant of EGFR in anaplastic astrocytoma and GBM [147]. Among those downstream effectors of EGFR pathway, MAPK and Akt but not STAT3 have been correlated to the progression of grade III astrocytoma to GBM (grade IV). In accordance, activated Akt but not pSTAT3-Y705 was predictive of a worse glioma prognosis.

In opposition to Mizoguchi et al. who evaluated STAT3 activity by quantifying pSTAT3-Y705 in tumours, Alvarez et al., assessed functional activation of STAT3 through expression of a subset of 12 genes admitted as defining the STAT3 signature [154]. This study found a positive correlation linking high expression level of STAT3 target genes with a poorer prognosis in glioma. However, they did not correlate phosphorylated STAT3 with gene expression in tumour samples. Another study established that pSTAT3-Y705 was a negative prognostic marker in anaplastic astrocytoma [145]. Furthermore, some other studies reaffirmed the bad prognostic value of the constitutive activation of pSTAT3-Y705 alone or in association with others mesenchymal markers such as C/EBP- $\beta$ and $\mathrm{C} / \mathrm{EBP}-\delta$ in GBM $[155,156]$.

The bad clinical meaning of STAT3 activation has recently been attested by the studies carried out by Lin et al., which established that high number of pSTAT3-Y705 and pSTAT3-S727 positive cells in GBM specimens, independently each other impact negatively the patients' progression-free survival and overall survival [152, 157]. Moreover, increased expression of the both makes worse the clinical outcome [152]. Since, pSTAT3-Y705 is not detected is some glioma specimens and does not accumulate in all glioma neoplastic cells [153], we speculate that it is not a major driver of GBM aggressiveness. In contrast, pSTAT3S727 detected is all neoplastic cells of all GBM specimens may be a best prognostic marker, provided that a discriminative detection assay is performed. 


\section{ROLE OF STAT3 IN GLIOMA TUMORIGENESIS AND AGGRESSIVENESS}

After phosphorylation and dimerization, STAT3-dimers translocate into the nucleus where they modulate expression of targeted genes harboring GAS sequences. STAT3 is involved in cell transformation but could also act in tumor cell including GBM stem-like cells to promote aggressiveness and resistance to current therapies. Thus, STAT3 signalling modulates expression of several genes implicated in transformation, survival, proliferation, immunosuppression, migration, invasion and neoangiogenesis (Figure 3).

\section{STAT3 in glioma genesis}

The first demonstration of STAT3 involvement in cell transformation rose from the observation that it was activated through pSTAT3-Y705 in fibroblasts and epithelial cells, which have been stably transformed by the Src oncogene tyrosine kinase [68]. Moreover, transgenic mice expressing $v$-src under control of GFAP gene regulatory elements developed transplantable astrocytoma that progress to GBM, thus providing evidence of the involvement of $v$-src and probably the consecutive activated STAT3 in initiating and promoting glioma genesis in a multistep way $[158,159]$. Consistent with the implication of activated STAT3 in the tumorigenesis of glioma, another analysis have evidenced that malignant transformation by $v$-src and maintenance of transformed phenotype require STAT3 that is however dispensable for normal cell growth [160]. The genuine oncogenic function of STAT3 by its own became clear with functional analysis using interfering negative or positive STAT3 dominant proteins. Negative dominant mutants rendered cells refractory to $v$-src transformation [81, 161] whereas positive dominants induced by themselves carcinogenesis $[162,163]$. The involvement of STAT3 in tumorigenesis is further explained by studies showing that pSTAT3-S727 localizes in mitochondria of diverse cell-types and sustain cellular functions including mitochondrial gene regulation [164], viability [165] and cell transformation [166]. However, a report demonstrated that STAT3 activation in glioma can also play a tumor suppressor function depending on tumor genetic background mainly on the mutational status of PTEN [167]. Rat orthotopic glioma models generated with the STAT3 S727A mutant (inactivated STAT3-S727) cell line, resulted in more aggressive tumors in comparison to the STAT3 WT expressing stable cell line tumors [62]. However, interpretation of such results should take in account an obvious concomitant increase in pSTAT3-Y705 level in the STAT3 S727A tumor cells. This increased pSTAT3-Y705 may be sufficient to boost tumor aggressiveness in the STAT3-S727A mutant. Concurrently modulating S727 and Y705 is essential in deciphering the contribution of both in tumorigenesis.

\section{STAT3 function in cell survival and proliferation}

Inhibition of STAT3 pathway by various strategies resulted in a decreased accumulation of anti-apoptotic gene products such as Survivin, Bcl-XL [168], Bcl-2, Mcl-1 [169] (Figure 3). In addition, inhibiting activated STAT3 reduced expression of cell cycle regulators: $c$-myc, cyclin D1 and cyclin E [170]. Those experiments have been conducted in vitro [169] as well as in vivo [170, 171]. Through control of regulators of cell cycle and apoptosis, inhibiting STAT3 activity resulted in increased cell death and decreased cell or tumor growth. Since STAT3 activity has been modulated by targeting pSTAT3-Y705 (pharmacological inhibitors, blocking antibodies, and dominant negative proteins) or total STAT3 protein accumulation (RNAi) or STAT3 dimers formation or binding to DNA (decoy oligonucleotides), the role of pSTAT3-S727 remained misunderstood in the cell fate control by STAT3. Interestingly, inhibiting STAT3 dimer formation and DNA-binding by the mean of STA-21, S3I-201[83], hydroxamic acid-based (SH5-07) and benzoic acid-based inhibitors (SH4-54) [172] STAT3 inhibitors which target the STAT3 SH2 domain resulted in apoptosis or decreased cell proliferation (assessed by low BrdU incorporation). This depended on the 
state of cell differentiation, on the cell culture conditions and on the profile of STAT3 phosphorylation (pSTAT3-Y705 or pSTAT3-S727). MicroRNA-506 (miR-506) and MicroRNA-519a (miR-519a) have been reported to act as tumor suppressors and inhibit cell proliferation in glioma by targeting STAT3 mRNA and decreasing expression of STAT3 target genes $[173,174]$. Any specific pSTAT3-S727 inhibitor should help in understanding the interference of pSTAT3-S727 and pSTAT3-Y705 in the control of cell survival and proliferation.

Regulation of cell survival by STAT3 is tightly linked to blocking of both apoptosis and autophagy since inhibiting active STAT3 by several means induced autophagy and concomitantly sensitized glioma cells to induction of apoptosis [175, 176]. These findings suggested that autophagy contributes to glioma escape to anticancer therapy.

\section{STAT3 activation role in glioma cell migration and invasion}

The use of inhibitors of STAT3 upstream regulators pointed that STAT3 might be involved in glioma cell migration and invasion [173, 174, 177, 178]. This inhibition of STAT3 has been linked to down-regulation of matrix metalloproteinase gene expression such as MMP2 [179], MMP9 and to epithelial-mesenchymal transition regulating genes like Snail [180] (Figure 3). STAT3 has also been shown to cooperate with other transcription factors such as NF-кB (p65) [181] and Nuclear factor I-X3 [182] in up-regulating respectively ICAM1 and $Y K L-40$, resulting in promotion of glioma cell migration and invasion.

\section{Role of STAT3 activation in local immune suppression}

STAT3 activation has been shown in several models to promote cancer cell immune escape by disturbing the processes involved in normal functioning of both innate and adaptive immune system components. Through plasma membrane interactions [183] and released cytokines such as IL-6, IL-8, IL-10, IP-10 (CXCL10), RANTES, TNF $\alpha$ [184], TGF $\beta$, and the PGE-2 prostaglandin [185], STAT3 activation in glioma cells including cell lines, primary cultured cells and cancer stem cells, has been shown in inducing immune tolerance. Through a mechanism that is not fully understood, STAT3 activation in glioma cells blocks differentiation, maturation and function of dendritic cells, inhibits T-cell proliferation [186] (Figure 3), induces T-cell anergy, T-regulatory cells, and immunosuppressive microglia [187]. An explicative mechanism is provided by the demonstration that activated STAT3 in glioma stem-like cells makes them secrete cytokines that induce paracrine activation of STAT3 in immune cells, thus contributing to their functional inactivation [188]. Furthermore, a very recent work established that glioma stem-like cells produce IL-6 and IL-10, which activate B7-H4 expression in tumor infiltrating macrophages through STAT3 signalling. B7-H4 expression in the tumor microenvironment, surrounding stroma and invasive edge, may contribute to the neoplastic cell escape from immune surveillance by blocking T-cell function [189]. Glioma-induced immunosuppression is potentiated by hypoxia [190]. It can be hampered or reversed by STAT3 inhibition [186, 191], suggesting the relevance of using STAT3 inhibitors in glioma immunotherapy. However inhibition of STAT3 did not prevent IL-6 induced suppression of Langerhans cell differentiation [192], indicating that STAT3 activation is not the only one mechanism of glioma-induced immune tolerance. Combined inhibition of STAT3 and the p38 MAPK pathways is therefore proposed as a synergic anticancer immunotherapeutic approach [185]. The role of STAT3 in tumor mediated immune suppression has been recently reviewed by Fergusson et al. [193].

\section{Contribution of STAT3 activation in glioma angiogenesis}

Through pSTAT3-Y705, STAT3 upregulates VEGF expression in glioma tumor cells in vitro and in vivo $[129,194]$. The role of pSTAT3-Y705-induced VEGF expression in 
glioma angiogenesis and tumor growth is confirmed since U87 human GBM cells expressing dominant-negative STAT3 induced slowly growing tumors with impaired neoangiogenesis [171]. More recently, this was confirmed by the antiangiogenic effect of JSI-124 JAK-STAT chemical inhibitor [195]. Furthermore, it has been shown that angiogenesis in glioma is accompanied by VEGF-A-induced loss of calpastatin (CAST) in endothelial cells. This downregulation of CAST triggers $\mu$-calpain-induced proteolysis of SOCS3 and subsequent hyperactivation of STAT3 which stimulates transcription of VEGF-C. Induced VEGF-C and VEGF-A act synergistically in angiogenesis [196]. Moreover, elevated ROS production plays a crucial role for STAT3 activation and for angiogenesis in hypoxic glioblastoma cells since blocking ROS resulted in STAT3 inhibition [197]. Clinical trials regarding anti-angiogenic therapy with Bevacizumab [198, 199], an anti-VEGF monoclonal antibody approved by US Food and Drug Administration (FDA) in recurrent glioma patient treatment, and chemical inhibitors of VEGFR such as Cediranib [200, 201] did not exhibit the expected benefit in terms of both safety and overall survival prolongation. Those unexpected results suggest that it might be relevant to integrate the modulation of STAT3 in the strategy of anti-angiogenic therapy because of its function, at least in part, as upstream regulator of not only angiogenesis, but also autophagy and hypoxia-induced biological effects $[14,175]$.

\section{Role of STAT3 in glioma stem-like cell maintenance}

GBM-derived stem-like cells displaying pSTAT3-Y705 and pSTAT3-S727 showed a modified pattern of STAT3 phosphorylation when grown in different conditions [83]. Using Stattic, an SH2 domain inhibitor, Villalva et al. showed that disruption of STAT3 function impaired neurosphere formation by slowing cell proliferation and inducing apoptosis of GBM stem-like cells [27]. STAT3 pathway phosphorylation on S727 or Y705 has been reported to be essential in the maintenance of not only the capacity of these stem-like cells to initiate neurospheres but also their multipotency [25, 83] and their immunosuppressive ability [186] (Figure 3). The carcinoembryonic antigen-related cell adhesion molecule Ceacam1L was described as a crucial factor in glioma stem-like cell maintenance and tumorigenesis by activating c-Src/STAT3 signalling [202]. In addition, Pigment Epithelium-Derived Factor (PEDF) has been identified as an EGFRvIII-STAT3 induced autocrine factor that promotes stemness of glioma stem-like cells [203]. The work of Talukdar et al. highlighted that pSTAT3-Y705-nanog signalling mediates the MDA-9/Syntenin (SDCBP) scaffold proteincontrolled stemness of GBM-stem-like cells while NOTCH1/c-Myc pathway governs the survival [204]. Mesenchymal stem cells isolated from human glioma sustain stemness of GBM-stem like cells by stimulating the IL-6/gp130/STAT3 axis in a coculture assay [205]. Therefore, GBM stem-like cell stemness generation and maintenance involve complex dialog between tumoral cells and stromal cells in which pSTAT3 isoforms are undoubtedly implicated. Such findings enhanced the need of STAT3 inhibitors because of relevance in targeting both tumoral cells including stem-like cells and stromal cells.

\section{Role of STAT3 activation in glioma resistance to standard treatment}

Treatment of malignant glioma is based on surgery, radiotherapy, and concomitant and adjuvant chemotherapy with temozolomide [4]. This standard treatment has been reported to prolong patient survival and to delay disease progression [206]. Despite this gold treatment, recurrence is still unavoidable in GBM and recurrent GBM are chemoresistant, mainly due to a selection of resistant tumor clones [6, 207].

The DNA-repair enzyme MGMT has been identified as conferring resistance to temozolomide. Repression of its encoding gene mainly by promoter methylation in tumors is a predicting factor of GBM response to alkylators [208, 209]. GBM, the highest degree of glioma malignancy harbor high level of STAT3 activation. This suggests an involvement of 
STAT3 pathway in glioma progression and a possible link with resistance to treatment. This is strengthened by a report showing that recurrent astrocytic glioma displayed an increased STAT3 protein accumulation compared to primary astrocytic tumors [210].

The involvement of the canonical pSTAT3-Y705 and/or the so far less studied pSTAT3-S727 in resistance to treatment is not yet well defined. Therefore published data are often incomplete because only one of the two phosphorylations (mainly pSTAT3-Y705) is assessed by authors resulting sometimes in contradictory results. Lee et al., reported an increase in total STAT3 and pSTAT3-S727 accumulation and a concomitant decrease in pSTAT3-Y705 in selected temozolomide-resistant cells, independently of MGMT expression, compared to (isogenic) parental [211]. Kohsaka et al., found that down-modulating STAT3 activity by shRNA or chemical inhibitor of pSTAT3-Y705 resulted in attenuated resistance to temozolomide and concomitant decrease in MGMT accumulation [146]. One explanation is the fact that temozomlomide resistance may not be governed only by MGMT. Such observations lead us to hypothesize that pSTAT3-Y705 and pSTAT3-S727 are two alternative drug resistance mechanism in GBM. STAT3 could affect chemoresistance via Y705 phosphorylation and MGMT expression or via S727 phosphorylation and other unknown mechanisms. It has also been reported that impairment of temozolomide resistance by inhibition of pSTAT3-Y705 is mediated at least in part through modulation of pAkt and $\beta$ catenin [212]. Thus, increased STAT3 activity by protein accumulation and/or increased level of pSTAT3-S727 or pSTAT3-Y705 is involved in temozolomide-resistance induction through complex mechanisms including upregulation of MGMT, pAkt and $\beta$-catenin activities. Further experiments are really needed to decipher implication of STAT3 signalling in temozolomide resistance.

Besides temozolomide-resistance, STAT3 activation is involved in resistance to radiation since suppressing pSTAT3-Y705 activity by Resveratrol weakened radioresistance and tumorigenic capacity of GBM cancer stem-like cells [213]. This is strengthened by the recent demonstration by Yuan et al. that suppression of autophagy augments radiosensitizing effect of STAT3 inhibition in U251 GBM cells [175]. Irradiation-induced proneural-tomesenchymal transition was also associated with activation of the STAT3 transcription factor, and the combination of pSTAT3-Y705 blockade using JAK2 inhibitors with radiation abrogated the mesenchymal transition and extended survival of in vivo glioma models [214]. We had however previously reported that inhibition of pSTAT3-Y705 by the mean of antigp130 neutralizing antibodies or by JSI-124 JAK-STAT chemical inhibitor did not circumvent SF763 GBM cell line radioresistance [215]. Conversely, Gö6976, a multiple kinase inhibitor, down-regulated pSTAT3-S727 and significantly reduced intrinsic radioresistance of some human GBM cell lines in which STAT3-Y705 was not activated [153]. Taken together, our results and the recent data suggest that the contribution of activated STAT3 (Y705 and/or S727) in GBM cell radioreresistance depends on cell type and/or on cell differentiation state. Specific inhibitor of pSTAT3-S727 may help highlight the contribution of each of STAT3-S727 and STAT3-Y705 phosphorylation in GBM response to radiotherapy. A relevant hypothesis is that pSTAT3-S727 might drive intrinsic radioresistance whereas pSTAT3-Y705 might sustain resistance due to tumor cell interaction with their microenvironment. 


\section{FUTURE DIRECTIONS TO IMPROVE GLIOBLASTOMAS PATIENTS TREATMENT BY STAT3 TARGETING}

Understanding the mechanisms involved in STAT3 pathway regulation is a current interest in the research for GBM therapy. Because pSTAT3-Y705 and pSTAT3-S727 have been reported as GBM markers that sustain some pathological processes of the genesis and of the aggressiveness of this disease, STAT3 inhibitors have been suggested as anti-cancer targeted therapeutic agents. Many pSTAT3-Y705 inhibitors have been engaged in clinical trials but there is not yet a proposed therapeutic pSTAT3-S727 inhibitor. However, recent data suggested that pSTAT3-S727 but not pSTAT3-Y705 is a constant pathological feature of activated STAT3 involved in the GBM resistance to gold standard therapy. These results underline the relevance of a combined inhibition of both pSTAT3-S727 and pSTAT3-Y705 in GBM therapy to counteract STAT3 pathological activation in glioma cells, glioma stem-like cells and stromal cells.

Ongoing clinical trials targeting somewhat STAT3 involve (i) drugs blocking cell membrane cytokine signalling mainly IL-6 or EGF axis, (ii) drugs inhibiting JAK1/2 intracellular upstream activators of pSTAT3-Y705 and (iii) specific inhibitors of STAT3. Among those drugs, only WP1066, a JAK2 inhibitor, is going to be tested in patients with glioma (NCT01904123). Consequently, it might not show effects on selective inhibition of STAT3. Such effects are expected from STAT3 decoy oligonucleotide [170], antisense oligonucleotide such as ISIS 481464 (ONIS-STAT3R3) [216] and AZD9150 [217] or direct inhibitors of STAT3-SH2 domain OBP-51602 [218, 219]. However, one of the major drawbacks of STAT3 targeting is the risk of toxicity due to the multiple cellular processes in which STAT3 play a physiological role. Targeting STAT3 for cancer treatment is one of the current challenges, chiefly in glioma. Therefore, identification and validation of new STAT3 inhibitors are needed to pursue the preclinical/clinical testing of broad inhibitors of both phosphorylations. Up to now, pSTAT3-Y05 has been easily blocked by several means but the clinical outcome was not satisfying. There is not yet any clinical trial based on pSTAT3-S727 inhibition. When waiting on the results of ongoing clinical trials (with WP1066 and with STAT3-SH2 inhibitors), it is not less relevant to set on research towards pSTAT3-S727 inhibition because of its involvement in several disease carrying mechanisms. We further recommend to examine both pSTAT3-S727 and pSTAT3-Y705 whenever studying the role of STAT3. This will highlight any prognostic or predictive value of STAT3 phosphorylation in glioma or in other diseases. It will moreover provide knowledge to refine STAT3-targeting preclinical and clinical trials. 


\section{ACKNOWLEDGEMENTS}

The CREaT/ EA7283-Auvergne University research team was supported by the Ligue Nationale Contre le Cancer (Comité du Puy-De-Dôme), of the Institut National du Cancer and by the Auvergne Region. ZG.O. was the recipient of a fellowship from the Ministère des Enseignements Secondaire et Supérieur, Burkina Faso. 


\section{FIGURE LEGENDS}

\section{Figure 1. STAT3 in the STAT protein family}

The N-terminal (N-Ter) domain is involved in interactions between neighboring DNA sitebound STAT dimers. The DNA binding domain (DNA) interacts with specific sequence of target-gene promoter. Coiled-coil (CC) domain interacts with partner proteins. Src Homology 2 (SH2) domain is responsible of dimer formation. The C-terminal Transactivation (TA) domain carries on the gene transcription activating function. LK indicates the linker domain.

\section{Figure 2. Conserved signalling pathways driving STAT3 phosphorylation.}

pSTAT3-Y705 is induced downstream gp130 phosphorylation and JAK2 recruitment. Activated JAK2 can be inhibited by SOCS3. Activated EGFR or its mutated versions including EGFRvIII induce pSTAT3-Y705. pSTAT3-Y705 can also be induced by intracellular kinases like BMX. PTPRD dephosphoylates pSTAT3-Y705 whereas PIAS3 directly inhibits activated STAT3. pSTAT3-S727 is directly mediated by PKCE or through an unknown mechanism (discontinuous arrow) downstream the NOTCH1 pathway activation. Activated STAT3 homodimerise, translocate to the nucleus and interact with GAS for target gene regulation. They up-regulates expression of several genes, including $H I F 1 \alpha, V E G F$, $S O C 3$, and $I L-6$. The released IL-6 contributes to auto-and paracrine activation of its pathway. pSTAT3-Y705 can interact with NFאB (p65). STAT3-NFאB oligomers bind to DNA and regulate several target genes, including Jagged 1 that encodes a NOTCH1 ligand. In absence of Notch Intracellular Domain (NICD), the DNA-bound RBPJ acts as a gene transcription repressor. It's interaction with the NICD switches it to a co-activator of gene expression.

\section{Figure 3. Role of STAT3 in glioblastoma tumorigenesis and tumor aggressiveness.}

Activation of STAT3 by phosphorylation on Y705 and S727 in non-neoplastic cell contributes to their transformation. pSTAT3-Y705 and pSTAT3-S727 are involved in stem cell proliferation and survival. They participate in the maintenance of stemness in GBM stemlike cells. In GBM cells, they sustain cell proliferation and the resistance to death induction by hypoxia or chemotherapy. pSTAT3-S727 sustains GBM cell intrinsic radioresistance. To restrain the phenomenon of hypoxia, tumor cells up-regulate, an overexpression of the VEGF through pSTAT3-Y705. VEGF induces paracrine activation of endothelial cell proliferation and neoangiogenesis. Moreover, pSTAT3-Y705 in tumor cells induces the release of several factors such as MMP that promote cell migration and non-neoplastic brain tissue invasion. Tissue invasion is also supported by pSTAT3-Y705-induced glioma cell expression of adhesion molecules such as ICAM-1. pSTAT3-Y705-induced release of chemokines and other cytokines like IL-6 contributes to inactivate immune cells or to block their maturation, then inducing immune tolerance of tumor cells. 


\section{REFERENCES}

1. Louis DN, Perry A, Reifenberger G, et al (2016) The 2016 World Health Organization Classification of Tumors of the Central Nervous System: a summary. Acta Neuropathol (Berl) 131:803-820. doi: 10.1007/s00401-016-1545-1

2. Ricard D, Idbaih A, Ducray F, et al (2012) Primary brain tumours in adults. Lancet Lond Engl 379:1984-1996. doi: 10.1016/S0140-6736(11)61346-9

3. Ohgaki H, Kleihues $\mathrm{P}$ (2013) The definition of primary and secondary glioblastoma. Clin Cancer Res Off J Am Assoc Cancer Res 19:764-772. doi: 10.1158/10780432.CCR-12-3002

4. Stupp R, Mason WP, van den Bent MJ, et al (2005) Radiotherapy plus concomitant and adjuvant temozolomide for glioblastoma. N Engl J Med 352:987-996. doi:

10.1056/NEJMoa043330

5. Chan JL, Lee SW, Fraass BA, et al (2002) Survival and Failure Patterns of High-Grade Gliomas After Three-Dimensional Conformal Radiotherapy. J Clin Oncol 20:16351642. doi: 10.1200/JCO.20.6.1635

6. Yin A, Cheng J, Zhang X, Liu B (2013) The treatment of glioblastomas: A systematic update on clinical Phase III trials. Crit Rev Oncol Hematol 87:265-282. doi: 10.1016/j.critrevonc.2013.01.007

7. Galli R, Binda E, Orfanelli U, et al (2004) Isolation and Characterization of Tumorigenic, Stem-like Neural Precursors from Human Glioblastoma. Cancer Res 64:7011-7021. doi: 10.1158/0008-5472.CAN-04-1364

8. Singh SK, Clarke ID, Terasaki M, et al (2003) Identification of a Cancer Stem Cell in Human Brain Tumors. Cancer Res 63:5821-5828.

9. Lee J, Son MJ, Woolard K, et al (2008) Epigenetic-Mediated Dysfunction of the Bone Morphogenetic Protein Developmental Pathway Inhibits Differentiation of Human Glioblastoma Tumor Initiating Cells. Cancer Cell 13:69-80. doi: 10.1016/j.ccr.2007.12.005

10. Wang Y, Yang J, Zheng H, et al (2009) Expression of mutant p53 proteins implicates a lineage relationship between neural stem cells and malignant astrocytic glioma in a murine model. Cancer Cell 15:514-526. doi: 10.1016/j.ccr.2009.04.001

11. Young GS, Macklin EA, Setayesh K, et al (2011) Longitudinal MRI evidence for decreased survival among periventricular glioblastoma. J Neurooncol 104:261-269. doi: 10.1007/s11060-010-0477-1

12. Jafri NF, Clarke JL, Weinberg V, et al (2013) Relationship of glioblastoma multiforme to the subventricular zone is associated with survival. Neuro-Oncol 15:91-96. doi: $10.1093 /$ neuonc/nos 268

13. Network CGAR (2008) Comprehensive genomic characterization defines human glioblastoma genes and core pathways. Nature 455:1061-1068. doi:

$10.1038 /$ nature07385 
14. Brantley EC, Benveniste EN (2008) STAT-3: A Molecular Hub for Signaling Pathways in Gliomas. Mol Cancer Res MCR. doi: 10.1158/1541-7786.MCR-07-2180

15. Wegenka UM, Buschmann J, Lütticken C, et al (1993) Acute-phase response factor, a nuclear factor binding to acute-phase response elements, is rapidly activated by interleukin-6 at the posttranslational level. Mol Cell Biol 13:276-288.

16. Darnell JE, Kerr IM, Stark GR (1994) Jak-STAT pathways and transcriptional activation in response to IFNs and other extracellular signaling proteins. Science 264:1415-1421.

17. Hervas-Stubbs S, Perez-Gracia JL, Rouzaut A, et al (2011) Direct Effects of Type I Interferons on Cells of the Immune System. Clin Cancer Res 17:2619-2627. doi: 10.1158/1078-0432.CCR-10-1114

18. Vallières L, Rivest S (2000) L'interleukine-6 dans le système nerveux central. médecine/sciences 16:936. doi: 10.4267/10608/1761

19. Miklossy G, Hilliard TS, Turkson J (2013) Therapeutic modulators of STAT signalling for human diseases. Nat Rev Drug Discov 12:611-629. doi: 10.1038/nrd4088

20. Szeląg M, Czerwoniec A, Wesoly J, Bluyssen HAR (2014) Comparative screening and validation as a novel tool to identify STAT-specific inhibitors. Eur J Pharmacol 740:417-420. doi: 10.1016/j.ejphar.2014.05.047

21. Yang J, Huang J, Dasgupta M, et al (2010) Reversible methylation of promoter-bound STAT3 by histone-modifying enzymes. Proc Natl Acad Sci U S A 107:21499-21504. doi: 10.1073/pnas.1016147107

22. O'Shea JJ, Kanno Y, Chen X, Levy DE (2005) Stat Acetylation--A Key Facet of Cytokine Signaling? Science 307:217-218. doi: 10.1126/science.1108164

23. Ray S, Boldogh I, Brasier AR (2005) STAT3 NH2-Terminal Acetylation Is Activated by the Hepatic Acute-Phase Response and Required for IL-6 Induction of Angiotensinogen. Gastroenterology 129:1616-1632. doi: 10.1053/j.gastro.2005.07.055

24. Yuan Z, Guan Y, Chatterjee D, Chin YE (2005) Stat3 Dimerization Regulated by Reversible Acetylation of a Single Lysine Residue. Science 307:269-273. doi: 10.1126/science. 1105166

25. Fan X, Khaki L, Zhu TS, et al (2010) NOTCH Pathway Blockade Depletes CD133Positive Glioblastoma Cells and Inhibits Growth of Tumor Neurospheres and Xenografts. STEM CELLS 28:5-16. doi: 10.1002/stem.254

26. Qin HR, Kim H-J, Kim J-Y, et al (2008) Activation of Stat3 through a Phosphomimetic Serine727 Promotes Prostate Tumorigenesis Independent of Tyrosine705 phosphorylation. Cancer Res 68:7736-7741. doi: 10.1158/0008-5472.CAN-08-1125

27. Villalva C, Martin-Lannerée S, Cortes U, et al (2011) STAT3 is essential for the maintenance of neurosphere-initiating tumor cells in patients with glioblastomas: A potential for targeted therapy? Int J Cancer 128:826-838. doi: 10.1002/ijc. 25416 
28. Furqan M, Mukhi N, Lee B, Liu D (2013) Dysregulation of JAK-STAT pathway in hematological malignancies and JAK inhibitors for clinical application. Biomark Res 1:5. doi: $10.1186 / 2050-7771-1-5$

29. Ren Z, Mao X, Mertens C, et al (2008) Crystal structure of unphosphorylated STAT3 core fragment. Biochem Biophys Res Commun 374:1-5. doi:

10.1016/j.bbrc.2008.04.049

30. Shuai K, Stark GR, Kerr IM, Darnell JE (1993) A single phosphotyrosine residue of Stat91 required for gene activation by interferon-gamma. Science 261:1744-1746.

31. Caldenhoven E, Dijk TB van, Solari R, et al (1996) STAT3ß, a Splice Variant of Transcription Factor STAT3, Is a Dominant Negative Regulator of Transcription. J Biol Chem 271:13221-13227. doi: 10.1074/jbc.271.22.13221

32. Chakraborty A, White SM, Schaefer TS, et al (1996) Granulocyte colony-stimulating factor activation of Stat 3 alpha and Stat 3 beta in immature normal and leukemic human myeloid cells. Blood 88:2442-2449.

33. Schaefer TS, Sanders LK, Nathans D (1995) Cooperative transcriptional activity of Jun and Stat3 beta, a short form of Stat3. Proc Natl Acad Sci U S A 92:9097-9101.

34. Hoey T, Zhang S, Schmidt N, et al (2003) Distinct requirements for the naturally occurring splice forms Stat $4 \alpha$ and Stat $4 \beta$ in IL-12 responses. EMBO J 22:4237-4248. doi: $10.1093 /$ emboj/cdg393

35. Wang D, Stravopodis D, Teglund S, et al (1996) Naturally occurring dominant negative variants of Stat5. Mol Cell Biol 16:6141-6148.

36. Ripperger JA, Fritz S, Richter K, et al (1995) Transcription Factors Stat3 and Stat5b Are Present in Rat Liver Nuclei Late in an Acute Phase Response and Bind Interleukin-6 Response Elements. J Biol Chem 270:29998-30006.

37. Patel BKR, Pierce JH, LaRochelle WJ (1998) Regulation of interleukin 4-mediated signaling by naturally occurring dominant negative and attenuated forms of human Stat6. Proc Natl Acad Sci U S A 95:172-177.

38. Chakraborty A, Tweardy DJ (1998) Granulocyte colony-stimulating factor activates a 72-kDa isoform of STAT3 in human neutrophils. J Leukoc Biol 64:675-680.

39. Azam M, Lee C, Strehlow I, Schindler C (1997) Functionally Distinct Isoforms of STAT5 Are Generated by Protein Processing. Immunity 6:691-701. doi: 10.1016/S1074-7613(00)80445-8

40. Caldenhoven E, van Dijk TB, Raaijmakers JA, et al (1999) Activation of a functionally distinct $80-\mathrm{kDa}$ STAT5 isoform by IL-5 and GM-CSF in human eosinophils and neutrophils. Mol Cell Biol Res Commun MCBRC 1:95-101. doi: 10.1006/mcbr.1999.0114

41. Sherman MA, Powell DR, Brown MA (2002) IL-4 Induces the Proteolytic Processing of Mast Cell STAT6. J Immunol 169:3811-3818. doi: 10.4049/jimmunol.169.7.3811 
42. Ilaria RL, Hawley RG, Etten RAV (1999) Dominant Negative Mutants Implicate STAT5 in Myeloid Cell Proliferation and Neutrophil Differentiation. Blood 93:4154-4166.

43. Piazza F, Valens J, Lagasse E, Schindler C (2000) Myeloid differentiation of FdCP1 cells is dependent on Stat5 processing. Blood 96:1358-1365.

44. Furqan M, Akinleye A, Mukhi N, et al (2013) STAT inhibitors for cancer therapy. J Hematol OncolJ Hematol Oncol 6:90. doi: 10.1186/1756-8722-6-90

45. Lavecchia A, Di Giovanni C, Novellino E (2011) STAT-3 inhibitors: state of the art and new horizons for cancer treatment. Curr Med Chem 18:2359-2375.

46. Yu H, Jove R (2004) The STATs of cancer - new molecular targets come of age. Nat Rev Cancer 4:97-105. doi: 10.1038/nrc1275

47. Catlett-Falcone R, Landowski TH, Oshiro MM, et al (1999) Constitutive activation of Stat 3 signaling confers resistance to apoptosis in human U266 myeloma cells. Immunity 10:105-115.

48. Kim JE, Patel M, Ruzevick J, et al (2014) STAT3 Activation in Glioblastoma: Biochemical and Therapeutic Implications. Cancers 6:376-395. doi: $10.3390 /$ cancers6010376

49. Zhong Z, Wen Z, Darnell JE Jr (1994) Stat3 and Stat4: members of the family of signal transducers and activators of transcription. Proc Natl Acad Sci U S A 91:4806-10.

50. Takeda K, Noguchi K, Shi W, et al (1997) Targeted disruption of the mouse Stat3 gene leads to early embryonic lethality. Proc Natl Acad Sci U S A 94:3801-3804.

51. Buckley RH, Wray BB, Belmaker EZ (1972) Extreme hyperimmunoglobulinemia E and undue susceptibility to infection. Pediatrics 49:59-70.

52. Davis SD, Schaller J, Wedgwood RJ (1966) Job's Syndrome. Recurrent, “cold”, staphylococcal abscesses. Lancet 1:1013-1015.

53. Holland SM, DeLeo FR, Elloumi HZ, et al (2007) STAT3 Mutations in the Hyper-IgE Syndrome. N Engl J Med 357:1608-1619. doi: 10.1056/NEJMoa073687

54. Kane A, Deenick EK, Ma CS, et al (2014) STAT3 is a central regulator of lymphocyte differentiation and function. Curr Opin Immunol 28:49-57. doi:

10.1016/j.coi.2014.01.015

55. Minegishi Y, Saito M, Tsuchiya S, et al (2007) Dominant-negative mutations in the DNA-binding domain of STAT3 cause hyper-IgE syndrome. Nature 448:1058-1062. doi: 10.1038/nature06096

56. Haapaniemi EM, Kaustio M, Rajala HLM, et al (2014) Autoimmunity, hypogammaglobulinemia, lymphoproliferation and mycobacterial disease in patients with dominant activating mutations in STAT3. Blood blood-2014-04-570101. doi: 10.1182/blood-2014-04-570101 
57. Milner JD, Vogel TP, Forbes L, et al (2015) Early-onset lymphoproliferation and autoimmunity caused by germline STAT3 gain-of-function mutations. Blood 125:591599. doi: 10.1182/blood-2014-09-602763

58. Jerez A, Clemente MJ, Makishima H, et al (2012) STAT3 mutations unify the pathogenesis of chronic lymphoproliferative disorders of NK cells and T-cell large granular lymphocyte leukemia. Blood 120:3048-3057. doi: 10.1182/blood-2012-06435297

59. Koskela HLM, Eldfors S, Ellonen P, et al (2012) Somatic STAT3 Mutations in Large Granular Lymphocytic Leukemia. N Engl J Med 366:1905-1913. doi: 10.1056/NEJMoa1114885

60. Malek RL, Halvorsen SW (1999) Ciliary neurotrophic factor and phorbol ester each decrease selected STAT3 pools in neuroblastoma cells by proteasome-dependent mechanisms. Cytokine 11:192-199. doi: 10.1006/cyto.1998.0421

61. Nie X, Ou-yang J, Xing Y, et al (2015) Paeoniflorin inhibits human glioma cells via STAT3 degradation by the ubiquitin-proteasome pathway. Drug Des Devel Ther 9:5611-5622. doi: 10.2147/DDDT.S93912

62. Mandal T, Bhowmik A, Chatterjee A, et al (2014) Reduced phosphorylation of Stat3 at Ser-727 mediated by casein kinase 2 - Protein phosphatase 2A enhances Stat3 Tyr-705 induced tumorigenic potential of glioma cells. Cell Signal 26:1725-1734. doi: 10.1016/j.cellsig.2014.04.003

63. Akira S, Nishio Y, Inoue M, et al (1994) Molecular cloning of APRF, a novel IFNstimulated gene factor $3 \mathrm{p} 91$-related transcription factor involved in the gp130-mediated signaling pathway. Cell 77:63-71.

64. Zhong Z, Wen Z, Darnell JE (1994) Stat3: a STAT family member activated by tyrosine phosphorylation in response to epidermal growth factor and interleukin-6. Science 264:95-98.

65. Grandis JR, Drenning SD, Chakraborty A, et al (1998) Requirement of Stat3 but not Stat 1 activation for epidermal growth factor receptor- mediated cell growth In vitro. J Clin Invest 102:1385-1392.

66. Sartor CI, Dziubinski ML, Yu C-L, et al (1997) Role of Epidermal Growth Factor Receptor and STAT-3 Activation in Autonomous Proliferation of SUM-102PT Human Breast Cancer Cells. Cancer Res 57:978-987.

67. Vignais ML, Sadowski HB, Watling D, et al (1996) Platelet-derived growth factor induces phosphorylation of multiple JAK family kinases and STAT proteins. Mol Cell Biol 16:1759-1769.

68. Yu CL, Meyer DJ, Campbell GS, et al (1995) Enhanced DNA-binding activity of a Stat3-related protein in cells transformed by the Src oncoprotein. Science 269:81-83.

69. Saharinen P, Ekman N, Sarvas K, et al (1997) The Bmx Tyrosine Kinase Induces Activation of the Stat Signaling Pathway, Which Is Specifically Inhibited by Protein Kinase C $\delta$. Blood 90:4341-4353. 
70. Wen X, Lin HH, Shih H-M, et al (1999) Kinase Activation of the Non-receptor Tyrosine Kinase Etk/BMX Alone Is Sufficient to Transactivate STAT-mediated Gene Expression in Salivary and Lung Epithelial Cells. J Biol Chem 274:38204-38210. doi: 10.1074/jbc.274.53.38204

71. Allen JC, Talab F, Zuzel M, et al (2011) c-Abl regulates Mcl-1 gene expression in chronic lymphocytic leukemia cells. Blood 117:2414-2422. doi: 10.1182/blood-201008-301176

72. Coppo P, Dusanter-Fourt I, Millot G, et al (2003) Constitutive and specific activation of STAT3 by BCR-ABL in embryonic stem cells. Oncogene 22:4102-4110. doi: 10.1038/sj.onc. 1206607

73. Chung J, Uchida E, Grammer TC, Blenis J (1997) STAT3 serine phosphorylation by ERK-dependent and -independent pathways negatively modulates its tyrosine phosphorylation. Mol Cell Biol 17:6508-6516.

74. Lim CP, Cao X (1999) Serine Phosphorylation and Negative Regulation of Stat3 by JNK. J Biol Chem 274:31055-31061. doi: 10.1074/jbc.274.43.31055

75. Wen Z, Darnell JE (1997) Mapping of Stat3 serine phosphorylation to a single residue (727) and evidence that serine phosphorylation has no influence on DNA binding of Stat 1 and Stat3. Nucleic Acids Res 25:2062-2067.

76. Jain N, Zhang T, Kee WH, et al (1999) Protein Kinase C $\delta$ Associates with and Phosphorylates Stat3 in an Interleukin-6-dependent Manner. J Biol Chem 274:2439224400. doi: $10.1074 /$ jbc.274.34.24392

77. Aziz MH, Hafeez BB, Sand JM, et al (2010) Protein kinase C? mediates Stat3Ser727 phosphorylation, Stat3-regulated gene expression and cell invasion in various human cancer cell lines via integration with MAPK cascade (RAF-1, MEK1/2, and ERK1/2). Oncogene 29:3100-3109. doi: 10.1038/onc.2010.63

78. Aziz MH, Manoharan HT, Church DR, et al (2007) Protein Kinase Ce Interacts with Signal Transducers and Activators of Transcription 3 (Stat3), Phosphorylates Stat3Ser727, and Regulates Its Constitutive Activation in Prostate Cancer. Cancer Res 67:8828-8838. doi: 10.1158/0008-5472.CAN-07-1604

79. Xu Y, Li Z, Zhang C, et al (2014) Knockdown of PKCe Expression Inhibits Growth, Induces Apoptosis and Decreases Invasiveness of Human Glioma Cells Partially Through Stat3. J Mol Neurosci 1-11. doi: 10.1007/s12031-014-0341-4

80. Lam E, Choi SH, Pareek TK, et al (2015) Cyclin-dependent kinase 5 represses Foxp3 gene expression and Treg development through specific phosphorylation of Stat 3 at Serine 727. Mol Immunol 67:317-24. doi: 10.1016/j.molimm.2015.06.015

81. Turkson J, Bowman T, Garcia R, et al (1998) Stat3 Activation by Src Induces Specific Gene Regulation and Is Required for Cell Transformation. Mol Cell Biol 18:2545-2552.

82. Miyakoshi M, Yamamoto M, Tanaka H, Ogawa K (2014) Serine 727 phosphorylation of STAT3: An early change in mouse hepatocarcinogenesis induced by neonatal treatment with diethylnitrosamine. Mol Carcinog 53:67-76. doi: 10.1002/mc.21949 
83. Sherry MM, Reeves A, Wu JK, Cochran BH (2009) STAT3 Is Required for Proliferation and Maintenance of Multipotency in Glioblastoma Stem Cells. STEM CELLS 27:23832392. doi: $10.1002 /$ stem. 185

84. Jiang Y, Janku F, Subbiah V, et al (2013) Germline PTPRD Mutations in Ewing Sarcoma: Biologic and Clinical Implications. Oncotarget 4:884-889.

85. Ostman A, Hellberg C, Böhmer FD (2006) Protein-tyrosine phosphatases and cancer. Nat Rev Cancer 6:307-320. doi: 10.1038/nrc1837

86. Hou J, Xu J, Jiang R, et al (2013) Estrogen-sensitive PTPRO expression represses hepatocellular carcinoma progression by control of STAT3. Hepatology 57:678-688. doi: 10.1002/hep.25980

87. Lund IK, Hansen JA, Andersen HS, et al (2005) Mechanism of protein tyrosine phosphatase 1B-mediated inhibition of leptin signalling. J Mol Endocrinol 34:339-351. doi: $10.1677 /$ jme.1.01694

88. Lee H, Morales LD, Slaga TJ, Kim DJ (2015) Activation of T-cell Protein-tyrosine Phosphatase Suppresses Keratinocyte Survival and Proliferation following UVB Irradiation. J Biol Chem 290:13-24. doi: 10.1074/jbc.M114.611681

89. Yamamoto T, Sekine Y, Kashima K, et al (2002) The nuclear isoform of proteintyrosine phosphatase TC-PTP regulates interleukin-6-mediated signaling pathway through STAT3 dephosphorylation. Biochem Biophys Res Commun 297:811-817. doi: 10.1016/S0006-291X(02)02291-X

90. Phromnoi K, Prasad S, Gupta SC, et al (2011) Dihydroxypentamethoxyflavone DownRegulates Constitutive and Inducible Signal Transducers and Activators of Transcription-3 through the Induction of Tyrosine Phosphatase SHP-1. Mol Pharmacol 80:889-899. doi: 10.1124/mol.111.073676

91. Yin S, Wu H, Lv J, et al (2014) SHP-1 Arrests Mouse Early Embryo Development through Downregulation of Nanog by Dephosphorylation of STAT3. PLoS ONE. doi: 10.1371/journal.pone.0086330

92. $\mathrm{Bu} \mathrm{Y,} \mathrm{Su} \mathrm{F,} \mathrm{Wang} \mathrm{X,} \mathrm{et} \mathrm{al} \mathrm{(2014)} \mathrm{Protein} \mathrm{tyrosine} \mathrm{phosphatase} \mathrm{PTPN9} \mathrm{regulates}$ erythroid cell development through STAT3 dephosphorylation in zebrafish. J Cell Sci 127:2761-2770. doi: $10.1242 /$ jcs. 145367

93. Su F, Ren F, Rong Y, et al (2012) Protein tyrosine phosphatase Meg2 dephosphorylates signal transducer and activator of transcription 3 and suppresses tumor growth in breast cancer. Breast Cancer Res BCR 14:R38. doi: 10.1186/bcr3134

94. Kim DJ, Tremblay ML, DiGiovanni J (2010) Protein Tyrosine Phosphatases, TC-PTP, SHP1, and SHP2, Cooperate in Rapid Dephosphorylation of Stat3 in Keratinocytes Following UVB Irradiation. PLoS ONE. doi: 10.1371/journal.pone.0010290

95. Su Z, Tian H, Song H, et al (2013) PTPN12 inhibits oral squamous epithelial carcinoma cell proliferation and invasion and can be used as a prognostic marker. Med Oncol Northwood Lond Engl 30:618. doi: 10.1007/s12032-013-0618-4 
96. Wakahara R, Kunimoto H, Tanino K, et al (2012) Phospho-Ser727 of STAT3 regulates STAT3 activity by enhancing dephosphorylation of phospho-Tyr705 largely through TC45. Genes Cells 17:132-145. doi: 10.1111/j.1365-2443.2011.01575.x

97. Xu Z-S, Zhang H-X, Zhang Y-L, et al (2016) PASD1 promotes STAT3 activity and tumor growth by inhibiting TC45-mediated dephosphorylation of STAT3 in the nucleus. J Mol Cell Biol 8:221-231. doi: 10.1093/jmcb/mjw005

98. Seshacharyulu P, Pandey P, Datta K, Batra SK (2013) Phosphatase: PP2A structural importance, regulation and its aberrant expression in cancer. Cancer Lett. doi: 10.1016/j.canlet.2013.02.036

99. Zhang J, Chen F, Li W, et al (2012) 14-3-3 $\zeta$ Interacts with Stat3 and Regulates Its Constitutive Activation in Multiple Myeloma Cells. PLoS ONE. doi: 10.1371/journal.pone.0029554

100. Ren F, Su F, Ning H, et al (2013) SIPAR negatively regulates STAT3 signaling and inhibits progression of melanoma. Cell Signal 25:2272-2280. doi:

10.1016/j.cellsig.2013.07.023

101. Wang P, Xue Y, Han Y, et al (2014) The STAT3-Binding Long Noncoding RNA lncDC Controls Human Dendritic Cell Differentiation. Science 344:310-313. doi: $10.1126 /$ science. 1251456

102. Chung CD, Liao J, Liu B, et al (1997) Specific Inhibition of Stat3 Signal Transduction by PIAS3. Science 278:1803-1805. doi: 10.1126/science.278.5344.1803

103. Palvimo JJ (2007) PIAS proteins as regulators of small ubiquitin-related modifier (SUMO) modifications and transcription. Biochem Soc Trans 35:1405-1408. doi: 10.1042/BST0351405

104. Starr R, Willson TA, Viney EM, et al (1997) A family of cytokine-inducible inhibitors of signalling. Nature 387:917-921. doi: 10.1038/43206

105. Lee D, Wang Y-H, Kalaitzidis D, et al (2016) Endogenous transmembrane protein UT2 inhibits pSTAT3 and suppresses hematological malignancy. J Clin Invest 126:13001310. doi: 10.1172/JCI84620

106. Dasgupta M, Unal H, Willard B, et al (2014) Critical Role for Lysine 685 in Gene Expression Mediated by Transcription Factor Unphosphorylated STAT3. J Biol Chem 289:30763-30771. doi: 10.1074/jbc.M114.603894

107. Yang J, Liao X, Agarwal MK, et al (2007) Unphosphorylated STAT3 accumulates in response to IL-6 and activates transcription by binding to NFкB. Genes Dev 21:13961408. doi: $10.1101 / \mathrm{gad} .1553707$

108. Gunaje JJ, Jayarama Bhat G (2001) Involvement of Tyrosine Phosphatase PTP1D in the Inhibition of Interleukin-6-Induced Stat3 Signaling by $\alpha$-Thrombin. Biochem Biophys Res Commun 288:252-257. doi: 10.1006/bbrc.2001.5759

109. Lin S, Saxena NK, Ding X, et al (2006) Leptin Increases Tissue Inhibitor of Metalloproteinase I (TIMP-1) Gene Expression by a Specificity Protein 1/Signal 
Transducer and Activator of Transcription 3 Mechanism. Mol Endocrinol Baltim Md 20:3376-3388. doi: 10.1210/me.2006-0177

110. Wang LH, Yang XY, Zhang X, et al (2004) Transcriptional Inactivation of STAT3 by PPAR $\gamma$ Suppresses IL-6-Responsive Multiple Myeloma Cells. Immunity 20:205-218. doi: 10.1016/S1074-7613(04)00030-5

111. Nakashima K, Yanagisawa M, Arakawa H, et al (1999) Synergistic Signaling in Fetal Brain by STAT3-Smad1 Complex Bridged by p300. Science 284:479-482. doi: 10.1126/science.284.5413.479

112. Matsuda T, Junicho A, Yamamoto T, et al (2001) Cross-Talk between Signal Transducer and Activator of Transcription 3 and Androgen Receptor Signaling in Prostate Carcinoma Cells. Biochem Biophys Res Commun 283:179-187. doi: $10.1006 /$ bbrc. 2001.4758

113. Yu Z, Zhang W, Kone BC (2002) Signal transducers and activators of transcription 3 (STAT3) inhibits transcription of the inducible nitric oxide synthase gene by interacting with nuclear factor kappaB. Biochem J 367:97-105. doi: 10.1042/BJ20020588

114. Zhang X, Wrzeszczynska MH, Horvath CM, Darnell JE (1999) Interacting Regions in Stat3 and c-Jun That Participate in Cooperative Transcriptional Activation. Mol Cell Biol 19:7138-7146.

115. Frattini V, Trifonov V, Chan JM, et al (2013) The integrated landscape of driver genomic alterations in glioblastoma. Nat Genet 45:1141-1149. doi: 10.1038/ng.2734

116. Lo H-W, Cao X, Zhu H, Ali-Osman F (2008) Constitutively Activated STAT3 Frequently Coexpresses with Epidermal Growth Factor Receptor in High-Grade Gliomas and Targeting STAT3 Sensitizes Them to Iressa and Alkylators. Clin Cancer Res 14:6042-6054. doi: 10.1158/1078-0432.CCR-07-4923

117. Chua CY, Liu Y, Granberg KJ, et al (2016) IGFBP2 potentiates nuclear EGFR-STAT3 signaling. Oncogene 35:738-747. doi: 10.1038/onc.2015.131

118. Chiou G-Y, Chien C-S, Wang M-L, et al (2013) Epigenetic regulation of the miR1423p/interleukin-6 circuit in glioblastoma. Mol Cell 52:693-706. doi: 10.1016/j.molcel.2013.11.009

119. Tchirkov A, Khalil T, Chautard E, et al (2007) Interleukin-6 gene amplification and shortened survival in glioblastoma patients. Br J Cancer 96:474-476. doi: 10.1038/sj.bjc. 6603586

120. Tchirkov A, Rolhion C, Bertrand S, et al (2001) IL-6 gene amplification and expression in human glioblastomas. Br J Cancer 85:518-522. doi: 10.1054/bjoc.2001.1942

121. Heinrich PC, Behrmann I, Muller-Newen G, et al (1998) Interleukin-6-type cytokine signalling through the gp130/Jak/STAT pathway. Biochem J 334:297-314.

122. Chen S-H, Benveniste EN (2004) Oncostatin M: a pleiotropic cytokine in the central nervous system. Cytokine Growth Factor Rev 15:379-391. doi:

10.1016/j.cytogfr.2004.06.002 
123. Grant SL, Begley CG (1999) The oncostatin M signalling pathway: reversing the neoplastic phenotype? Mol Med Today 5:406-412. doi: 10.1016/S1357-4310(99)015403

124. Natesh K, Bhosale D, Desai A, et al (2015) Oncostatin-M differentially regulates mesenchymal and proneural signature genes in gliomas via STAT3 signaling. Neoplasia N Y N 17:225-237. doi: 10.1016/j.neo.2015.01.001

125. Jahani-Asl A, Yin H, Soleimani VD, et al (2016) Control of glioblastoma tumorigenesis by feed-forward cytokine signaling. Nat Neurosci 19:798-806. doi: 10.1038/nn.4295

126. Wang H, Lathia JD, Wu Q, et al (2009) Targeting Interleukin 6 Signaling Suppresses Glioma Stem Cell Survival and Tumor Growth. Stem Cells Dayt Ohio 27:2393-2404. doi: 10.1002/stem.188

127. Liu Q, Li G, Li R, et al (2010) IL-6 promotion of glioblastoma cell invasion and angiogenesis in U251 and T98G cell lines. J Neurooncol 100:165-176. doi: $10.1007 / \mathrm{s} 11060-010-0158-0$

128. Akil H, Abbaci A, Lalloué F, et al (2015) IL22/IL-22R pathway induces cell survival in human glioblastoma cells. PloS One 10:e0119872. doi: 10.1371/journal.pone.0119872

129. Loeffler S, Fayard B, Weis J, Weissenberger J (2005) Interleukin-6 induces transcriptional activation of vascular endothelial growth factor (VEGF) in astrocytes in vivo and regulates VEGF promoter activity in glioblastoma cells via direct interaction between STAT3 and Sp1. Int J Cancer 115:202-213. doi: 10.1002/ijc.20871

130. Xu Q, Briggs J, Park S, et al (2005) Targeting Stat3 blocks both HIF-1 and VEGF expression induced by multiple oncogenic growth signaling pathways. Oncogene 24:5552-5560. doi: 10.1038/sj.onc.1208719

131. Ren (2011) Selective inhibition of PDGFR by imatinib elicits the sustained activation of ERK and downstream receptor signaling in malignant glioma cells. Int J Oncol. doi: 10.3892/ijo.2010.861

132. Guryanova OA, Wu Q, Cheng L, et al (2011) Non-Receptor Tyrosine Kinase BMX Maintains Self-Renewal and Tumorigenic Potential of Glioblastoma Stem Cells by Activating STAT3. Cancer Cell 19:498-511. doi: 10.1016/j.ccr.2011.03.004

133. Sharif TR, Sharif M (1999) Overexpression of protein kinase C epsilon in astroglial brain tumor derived cell lines and primary tumor samples. Int J Oncol. doi:

10.3892/ijo.15.2.237

134. Androutsellis-Theotokis A, Leker RR, Soldner F, et al (2006) Notch signalling regulates stem cell numbers in vitro and in vivo. Nature 442:823-826. doi: 10.1038/nature04940

135. Garner JM, Fan M, Yang CH, et al (2013) Constitutive Activation of Signal Transducer and Activator of Transcription 3 (STAT3) and Nuclear Factor $\kappa B$ Signaling in Glioblastoma Cancer Stem Cells Regulates the Notch Pathway. J Biol Chem 288:2616726176. doi: 10.1074/jbc.M113.477950 
136. Brantley EC, Nabors LB, Gillespie GY, et al (2008) Loss of PIAS3 Expression in Glioblastoma Multiforme Tumors: Implications for STAT-3 Activation and Gene Expression. Clin Cancer Res Off J Am Assoc Cancer Res. doi: 10.1158/10780432.CCR-08-0618

137. Yasukawa H, Sasaki A, Yoshimura A (2000) Negative regulation of cytokine signaling pathways. Annu Rev Immunol 18:143-164. doi: 10.1146/annurev.immunol.18.1.143

138. Yoshimura A, Naka T, Kubo M (2007) SOCS proteins, cytokine signalling and immune regulation. Nat Rev Immunol 7:454-465. doi: 10.1038/nri2093

139. Sutherland KD, Lindeman GJ, Choong DYH, et al (2004) Differential hypermethylation of SOCS genes in ovarian and breast carcinomas. Oncogene 23:7726-7733. doi: 10.1038/sj.onc. 1207787

140. Zhou H, Miki R, Eeva M, et al (2007) Reciprocal regulation of SOCS 1 and SOCS3 enhances resistance to ionizing radiation in glioblastoma multiforme. Clin Cancer Res Off J Am Assoc Cancer Res 13:2344-2353. doi: 10.1158/1078-0432.CCR-06-2303

141. Solomon DA, Kim J-S, Cronin JC, et al (2008) Mutational Inactivation of PTPRD in Glioblastoma Multiforme and Malignant Melanoma. Cancer Res 68:10300-10306. doi: 10.1158/0008-5472.CAN-08-3272

142. Veeriah S, Brennan C, Meng S, et al (2009) The tyrosine phosphatase PTPRD is a tumor suppressor that is frequently inactivated and mutated in glioblastoma and other human cancers. Proc Natl Acad Sci U S A 106:9435-9440. doi: 10.1073/pnas.0900571106

143. Ortiz B, Fabius AWM, Wu WH, et al (2014) Loss of the tyrosine phosphatase PTPRD leads to aberrant STAT3 activation and promotes gliomagenesis. Proc Natl Acad Sci 111:8149-8154. doi: 10.1073/pnas.1401952111

144. Lee K, Byun K, Hong W, et al (2013) Proteome-wide discovery of mislocated proteins in cancer. Genome Res 23:1283-1294. doi: 10.1101/gr.155499.113

145. Abou-Ghazal M, Yang DS, Qiao W, et al (2008) The Incidence, Correlation with Tumor-Infiltrating Inflammation, and Prognosis of Phosphorylated STAT3 Expression in Human Gliomas. Clin Cancer Res 14:8228-8235. doi: 10.1158/1078-0432.CCR-081329

146. Kohsaka S, Wang L, Yachi K, et al (2012) STAT3 Inhibition Overcomes Temozolomide Resistance in Glioblastoma by Downregulating MGMT Expression. Mol Cancer Ther 11:1289-1299. doi: 10.1158/1535-7163.MCT-11-0801

147. Mizoguchi M, Betensky RA, Batchelor TT, et al (2006) Activation of STAT3, MAPK, and AKT in malignant astrocytic gliomas: correlation with EGFR status, tumor grade, and survival. J Neuropathol Exp Neurol 65:1181-1188. doi: 10.1097/01.jnen.0000248549.14962.b2

148. Wang H, Wang H, Zhang W, et al (2004) Analysis of the activation status of Akt, NFkB, and Stat3 in human diffuse gliomas. Lab Invest 84:941-951. doi:

10.1038/labinvest.3700123 
149. Birner P, Toumangelova-Uzeir K, Natchev S, Guentchev M (2010) STAT3 tyrosine phosphorylation influences survival in glioblastoma. J Neurooncol 100:339-343. doi: 10.1007/s11060-010-0195-8

150. Schaefer LK, Ren Z, Fuller GN, Schaefer TS (2002) Constitutive activation of Stat3alpha in brain tumors: localization to tumor endothelial cells and activation by the endothelial tyrosine kinase receptor (VEGFR-2). Oncogene 21:2058-2065. doi: 10.1038/sj.onc. 1205263

151. Aoki H, Iwado E, Eller MS, et al (2007) Telomere 3' overhang-specific DNA oligonucleotides induce autophagy in malignant glioma cells. FASEB J 21:2918-2930. doi: 10.1096/fj.06-6941com

152. Lin G-S, Chen Y-P, Lin Z-X, et al (2014) STAT3 serine 727 phosphorylation influences clinical outcome in glioblastoma. Int J Clin Exp Pathol 7:3141-3149.

153. Ouédraogo ZG, Müller-Barthélémy M, Kemeny J-L, et al (2016) STAT3 Serine 727 Phosphorylation: A Relevant Target to Radiosensitize Human Glioblastoma. Brain Pathol Zurich Switz 26:18-30. doi: 10.1111/bpa.12254

154. Alvarez JV, Mukherjee N, Chakravarti A, et al (2007) A STAT3 Gene Expression Signature in Gliomas is Associated with a Poor Prognosis. Transl Oncogenomics 2:99105.

155. Carro MS, Lim WK, Alvarez MJ, et al (2010) The transcriptional network for mesenchymal transformation of brain tumors. Nature 463:318-325. doi: 10.1038/nature08712

156. Cooper LAD, Gutman DA, Chisolm C, et al (2012) The Tumor Microenvironment Strongly Impacts Master Transcriptional Regulators and Gene Expression Class of Glioblastoma. Am J Pathol 180:2108-2119. doi: 10.1016/j.ajpath.2012.01.040

157. Lin G-S, Yang L-J, Wang X-F, et al (2014) STAT3 Tyr705 phosphorylation affects clinical outcome in patients with newly diagnosed supratentorial glioblastoma. Med Oncol 31:1-7. doi: 10.1007/s12032-014-0924-5

158. Smilowitz HM, Weissenberger J, Weis J, et al (2007) Orthotopic transplantation of vsrc-expressing glioma cell lines into immunocompetent mice: establishment of a new transplantable in vivo model for malignant glioma. J Neurosurg 106:652-659. doi: $10.3171 /$ jns.2007.106.4.652

159. Weissenberger J, Steinbach JP, Malin G, et al (1997) Development and malignant progression of astrocytomas in GFAP-v-src transgenic mice. Oncogene 14:2005-2013. doi: $10.1038 /$ sj.onc. 1201168

160. Schlessinger K, Levy DE (2005) Malignant transformation but not normal cell growth depend on STAT3. Cancer Res 65:5828-5834. doi: 10.1158/0008-5472.CAN-05-0317

161. Bromberg JF, Horvath CM, Besser D, et al (1998) Stat3 Activation Is Required for Cellular Transformation by v-src. Mol Cell Biol 18:2553-2558. 
162. Bromberg JF, Wrzeszczynska MH, Devgan G, et al (1999) Stat3 as an Oncogene. Cell 98:295-303. doi: 10.1016/S0092-8674(00)81959-5

163. Dechow TN, Pedranzini L, Leitch A, et al (2004) Requirement of matrix metalloproteinase-9 for the transformation of human mammary epithelial cells by Stat3C. Proc Natl Acad Sci U S A 101:10602-10607. doi: 10.1073/pnas.0404100101

164. Macias E, Rao D, Carbajal S, et al (2014) Stat3 binds to mtDNA and regulates mitochondrial gene expression in keratinocytes. J Invest Dermatol 134:1971-80. doi: 10.1038/jid.2014.68

165. Capron C, Jondeau K, Casetti L, et al (2014) Viability and stress protection of chronic lymphoid leukemia cells involves overactivation of mitochondrial phosphoSTAT3Ser727. Cell Death Dis 5:e1451. doi: 10.1038/cddis.2014.393

166. Yu C, Huo X, Agoston AT, et al (2015) Mitochondrial STAT3 contributes to transformation of Barrett's epithelial cells that express oncogenic Ras in a p53independent fashion. Am J Physiol Gastrointest Liver Physiol 309:G146-61. doi: 10.1152/ajpgi.00462.2014

167. de la Iglesia N, Konopka G, Lim KL, et al (2008) Deregulation of a STAT3-IL8 Signaling Pathway Promotes Human Glioblastoma Cell Proliferation and Invasiveness. J Neurosci Off J Soc Neurosci 28:5870-5878. doi: 10.1523/JNEUROSCI.5385-07.2008

168. Konnikova L, Kotecki M, Kruger MM, Cochran BH (2003) Knockdown of STAT3 expression by RNAi induces apoptosis in astrocytoma cells. BMC Cancer 3:23. doi: 10.1186/1471-2407-3-23

169. Rahaman SO, Harbor PC, Chernova O, et al (2002) Inhibition of constitutively active Stat 3 suppresses proliferation and induces apoptosis in glioblastoma multiforme cells. Oncogene 21:8404-8413. doi: 10.1038/sj.onc.1206047

170. Shen J, Li R, Li G (2009) Inhibitory effects of decoy-ODN targeting activated STAT3 on human glioma growth in vivo. Vivo Athens Greece 23:237-243.

171. Dasgupta A, Raychaudhuri B, Haqqi T, et al (2009) Stat3 activation is required for the growth of U87 cell-derived tumours in mice. Eur J Cancer 45:677-684. doi: 10.1016/j.ejca.2008.11.027

172. Yue P, Lopez-Tapia F, Paladino D, et al (2016) Hydroxamic Acid and Benzoic AcidBased STAT3 Inhibitors Suppress Human Glioma and Breast Cancer Phenotypes In Vitro and In Vivo. Cancer Res 76:652-663. doi: 10.1158/0008-5472.CAN-14-3558

173. Peng T, Zhou L, Zuo L, Luan Y (2016) MiR-506 functions as a tumor suppressor in glioma by targeting STAT3. Oncol Rep 35:1057-1064. doi: 10.3892/or.2015.4406

174. Hong L, Ya-Wei L, Hai W, et al (2016) MiR-519a functions as a tumor suppressor in glioma by targeting the oncogenic STAT3 pathway. J Neurooncol 128:35-45. doi: $10.1007 / \mathrm{s} 11060-016-2095-\mathrm{z}$ 
175. Yuan X, Du J, Hua S, et al (2015) Suppression of autophagy augments the radiosensitizing effects of STAT3 inhibition on human glioma cells. Exp Cell Res 330:267-276. doi: 10.1016/j.yexcr.2014.09.006

176. Zou M, Hu C, You Q, et al (2015) Oroxylin A induces autophagy in human malignant glioma cells via the mTOR-STAT3-Notch signaling pathway. Mol Carcinog 54:13631375. doi: $10.1002 / \mathrm{mc} .22212$

177. Jhanwar-Uniyal (2009) Involvement of mTORC1 and mTORC2 in regulation of glioblastoma multiforme growth and motility. Int J Oncol. doi: 10.3892/ijo_00000386

178. Senft C, Priester M, Polacin M, et al (2011) Inhibition of the JAK-2/STAT3 signaling pathway impedes the migratory and invasive potential of human glioblastoma cells. $\mathbf{J}$ Neurooncol 101:393-403. doi: 10.1007/s11060-010-0273-y

179. Li (2010) IL-6 augments the invasiveness of U87MG human glioblastoma multiforme cells via up-regulation of MMP-2 and fascin-1. Oncol Rep. doi: 10.3892/or_00000795

180. Priester M, Copanaki E, Vafaizadeh V, et al (2013) STAT3 silencing inhibits glioma single cell infiltration and tumor growth. Neuro-Oncol 15:840-852. doi: $10.1093 /$ neuonc/not025

181. Kesanakurti D, Chetty C, Maddirela DR, et al (2013) Essential Role of Cooperative NF?B and Stat3 Recruitment to ICAM-1 Intronic Consensus Elements in the Regulation of Radiation-induced Invasion and Migration in Glioma. Oncogene. doi: 10.1038/onc. 2012.546

182. Singh SK, Bhardwaj R, Wilczynska KM, et al (2011) A Complex of Nuclear Factor I-X3 and STAT3 Regulates Astrocyte and Glioma Migration through the Secreted Glycoprotein YKL-40. J Biol Chem 286:39893-39903. doi: 10.1074/jbc.M111.257451

183. Xu L, Xiao H, Xu M, et al (2011) Glioma-derived T Cell Immunoglobulin- and Mucin Domain-containing Molecule-4 (TIM4) Contributes to Tumor Tolerance. J Biol Chem 286:36694-36699. doi: 10.1074/jbc.M111.292540

184. See AP, Han JE, Phallen J, et al (2012) The role of STAT3 activation in modulating the immune microenvironment of GBM. J Neurooncol 110:359-368. doi: 10.1007/s11060012-0981-6

185. Oosterhoff D, Lougheed S, van de Ven R, et al (2012) Tumor-mediated inhibition of human dendritic cell differentiation and function is consistently counteracted by combined p38 MAPK and STAT3 inhibition. Oncoimmunology 1:649-658. doi: 10.4161/onci.20365

186. Wei J, Barr J, Kong L-Y, et al (2010) Glioblastoma cancer-initiating cells inhibit T cell proliferation and effector responses by the STAT3 pathway. Mol Cancer Ther 9:67-78. doi: 10.1158/1535-7163.MCT-09-0734

187. Wu A, Wei J, Kong L-Y, et al (2010) Glioma cancer stem cells induce immunosuppressive macrophages/microglia. Neuro-Oncol 12:1113-1125. doi: 10.1093/neuonc/noq082 
188. Fujita M, Zhu X, Sasaki K, et al (2008) Inhibition of STAT3 Promotes the Efficacy of Adoptive Transfer Therapy Using Type-1 CTLs by Modulation of the Immunological Microenvironment in a Murine Intracranial Glioma. J Immunol 180:2089-2098. doi: 10.4049/jimmunol.180.4.2089

189. Yao Y, Ye H, Qi Z, et al (2016) B7-H4(B7x)-Mediated Cross-talk between GliomaInitiating Cells and Macrophages via the IL6/JAK/STAT3 Pathway Lead to Poor Prognosis in Glioma Patients. Clin Cancer Res Off J Am Assoc Cancer Res 22:27782790. doi: 10.1158/1078-0432.CCR-15-0858

190. Wei J, Wu A, Kong L-Y, et al (2011) Hypoxia Potentiates Glioma-Mediated Immunosuppression. PLoS ONE. doi: 10.1371/journal.pone.0016195

191. Hussain SF, Kong L-Y, Jordan J, et al (2007) A Novel Small Molecule Inhibitor of Signal Transducers and Activators of Transcription 3 Reverses Immune Tolerance in Malignant Glioma Patients. Cancer Res 67:9630-9636. doi: 10.1158/0008-5472.CAN07-1243

192. van Cruijsen H, Oosterhoff D, Lindenberg JJ, et al (2011) Glioblastoma-induced inhibition of Langerhans cell differentiation from CD34(+) precursors is mediated by IL6 but unaffected by JAK2/STAT3 inhibition. Immunotherapy 3:1051-1061. doi: 10.2217/imt.11.107

193. Ferguson SD, Srinivasan VM, Heimberger AB (2015) The role of STAT3 in tumormediated immune suppression. J Neurooncol 123:385-394. doi: 10.1007/s11060-0151731-3

194. Kang S-H, Yu MO, Park K-J, et al (2010) Activated STAT3 regulates hypoxia-induced angiogenesis and cell migration in human glioblastoma. Neurosurgery 67:1386-1395; discussion 1395. doi: 10.1227/NEU.0b013e3181f1c0cd

195. Yuan G, Yan S, Xue H, et al (2015) JSI-124 suppresses invasion and angiogenesis of glioblastoma cells in vitro. PloS One 10:e0118894. doi: 10.1371/journal.pone.0118894

196. Miyazaki T, Taketomi Y, Saito Y, et al (2015) Calpastatin counteracts pathological angiogenesis by inhibiting suppressor of cytokine signaling 3 degradation in vascular endothelial cells. Circ Res 116:1170-1181. doi: 10.1161/CIRCRESAHA.116.305363

197. Yu MO, Park K-J, Park D-H, et al (2015) Reactive oxygen species production has a critical role in hypoxia-induced Stat 3 activation and angiogenesis in human glioblastoma. J Neurooncol 125:55-63. doi: 10.1007/s11060-015-1889-8

198. Chinot OL, Wick W, Cloughesy T (2014) Bevacizumab for newly diagnosed glioblastoma. N Engl J Med 370:2049.

199. Gilbert MR, Dignam JJ, Armstrong TS, et al (2014) A randomized trial of bevacizumab for newly diagnosed glioblastoma. N Engl J Med 370:699-708. doi:

10.1056/NEJMoa1308573

200. Batchelor TT, Mulholland P, Neyns B, et al (2013) Phase III randomized trial comparing the efficacy of cediranib as monotherapy, and in combination with lomustine, versus 
lomustine alone in patients with recurrent glioblastoma. J Clin Oncol Off J Am Soc Clin Oncol 31:3212-3218. doi: 10.1200/JCO.2012.47.2464

201. Gerstner ER, Ye X, Duda DG, et al (2015) A phase I study of cediranib in combination with cilengitide in patients with recurrent glioblastoma. Neuro-Oncol 17:1386-1392. doi: 10.1093/neuonc/nov085

202. Kaneko S, Nakatani Y, Takezaki T, et al (2015) Ceacam1L Modulates STAT3 Signaling to Control the Proliferation of Glioblastoma-Initiating Cells. Cancer Res 75:4224-4234. doi: 10.1158/0008-5472.CAN-15-0412

203. Yin J, Park G, Kim TH, et al (2015) Pigment Epithelium-Derived Factor (PEDF) Expression Induced by EGFRvIII Promotes Self-renewal and Tumor Progression of Glioma Stem Cells. PLoS Biol 13:e1002152. doi: 10.1371/journal.pbio.1002152

204. Talukdar S, Das SK, Pradhan AK, et al (2016) Novel function of MDA-9/Syntenin (SDCBP) as a regulator of survival and stemness in glioma stem cells. Oncotarget. doi: 10.18632/oncotarget.10851

205. Hossain A, Gumin J, Gao F, et al (2015) Mesenchymal Stem Cells Isolated From Human Gliomas Increase Proliferation and Maintain Stemness of Glioma Stem Cells Through the IL-6/gp130/STAT3 Pathway. Stem Cells Dayt Ohio 33:2400-2415. doi: 10.1002/stem.2053

206. Hart MG, Garside R, Rogers G, et al (1996) Temozolomide for high grade glioma. Cochrane Database Syst. Rev.

207. Kunwar S, Chang S, Westphal M, et al (2010) Phase III randomized trial of CED of IL13-PE38QQR vs Gliadel wafers for recurrent glioblastoma. Neuro-Oncol 12:871-881. doi: 10.1093/neuonc/nop054

208. Hegi ME, Diserens A-C, Gorlia T, et al (2005) MGMT Gene Silencing and Benefit from Temozolomide in Glioblastoma. N Engl J Med 352:997-1003. doi: 10.1056/NEJMoa043331

209. Weller M, Stupp R, Reifenberger G, et al (2010) MGMT promoter methylation in malignant gliomas: ready for personalized medicine? Nat Rev Neurol 6:39-51. doi: 10.1038/nrneurol.2009.197

210. Zhang K, Pang B, Xin T, et al (2011) Increased Signal Transducer and Activator of Transcription 3 (STAT3) and Decreased Cyclin D1 in Recurrent Astrocytic Tumours Compared with Paired Primary Astrocytic Tumours. J Int Med Res 39:2103-2109. doi: $10.1177 / 147323001103900606$

211. Lee E-S, Ko K-K, Joe YA, et al (2011) Inhibition of STAT3 reverses drug resistance acquired in temozolomide-resistant human glioma cells. Oncol Lett 2:115-121. doi: 10.3892/ol.2010.210

212. Kang C (2011) Inhibition of STAT3 reverses alkylator resistance through modulation of the AKT and $\beta$-catenin signaling pathways. Oncol Rep. doi: 10.3892/or.2011.1396 
213. Yang Y-P, Chang Y-L, Huang P-I, et al (2012) Resveratrol suppresses tumorigenicity and enhances radiosensitivity in primary glioblastoma tumor initiating cells by inhibiting the STAT3 axis. J Cell Physiol 227:976-993. doi: 10.1002/jcp.22806

214. Lau J, Ilkhanizadeh S, Wang S, et al (2015) STAT3 Blockade Inhibits RadiationInduced Malignant Progression in Glioma. Cancer Res 75:4302-4311. doi: 10.1158/0008-5472.CAN-14-3331

215. Chautard E, Loubeau G, Tchirkov A, et al (2010) Akt signaling pathway: a target for radiosensitizing human malignant glioma. Neuro-Oncol 12:434-443. doi: 10.1093/neuonc/nop059

216. Burel SA, Han S-R, Lee H-S, et al (2013) Preclinical evaluation of the toxicological effects of a novel constrained ethyl modified antisense compound targeting signal transducer and activator of transcription 3 in mice and cynomolgus monkeys. Nucleic Acid Ther 23:213-227. doi: 10.1089/nat.2013.0422

217. Hong D, Kurzrock R, Kim Y, et al (2015) AZD9150, a next-generation antisense oligonucleotide inhibitor of STAT3 with early evidence of clinical activity in lymphoma and lung cancer. Sci Transl Med 7:314ra185. doi: 10.1126/scitranslmed.aac5272

218. Ogura M, Uchida T, Terui Y, et al (2015) Phase I study of OPB-51602, an oral inhibitor of signal transducer and activator of transcription 3, in patients with relapsed/refractory hematological malignancies. Cancer Sci 106:896-901. doi: 10.1111/cas.12683

219. Wong AL, Soo RA, Tan DS, et al (2015) Phase I and biomarker study of OPB-51602, a novel signal transducer and activator of transcription (STAT) 3 inhibitor, in patients with refractory solid malignancies. Ann Oncol Off J Eur Soc Med Oncol ESMO 26:9981005. doi: 10.1093/annonc/mdv026 
Figure 1

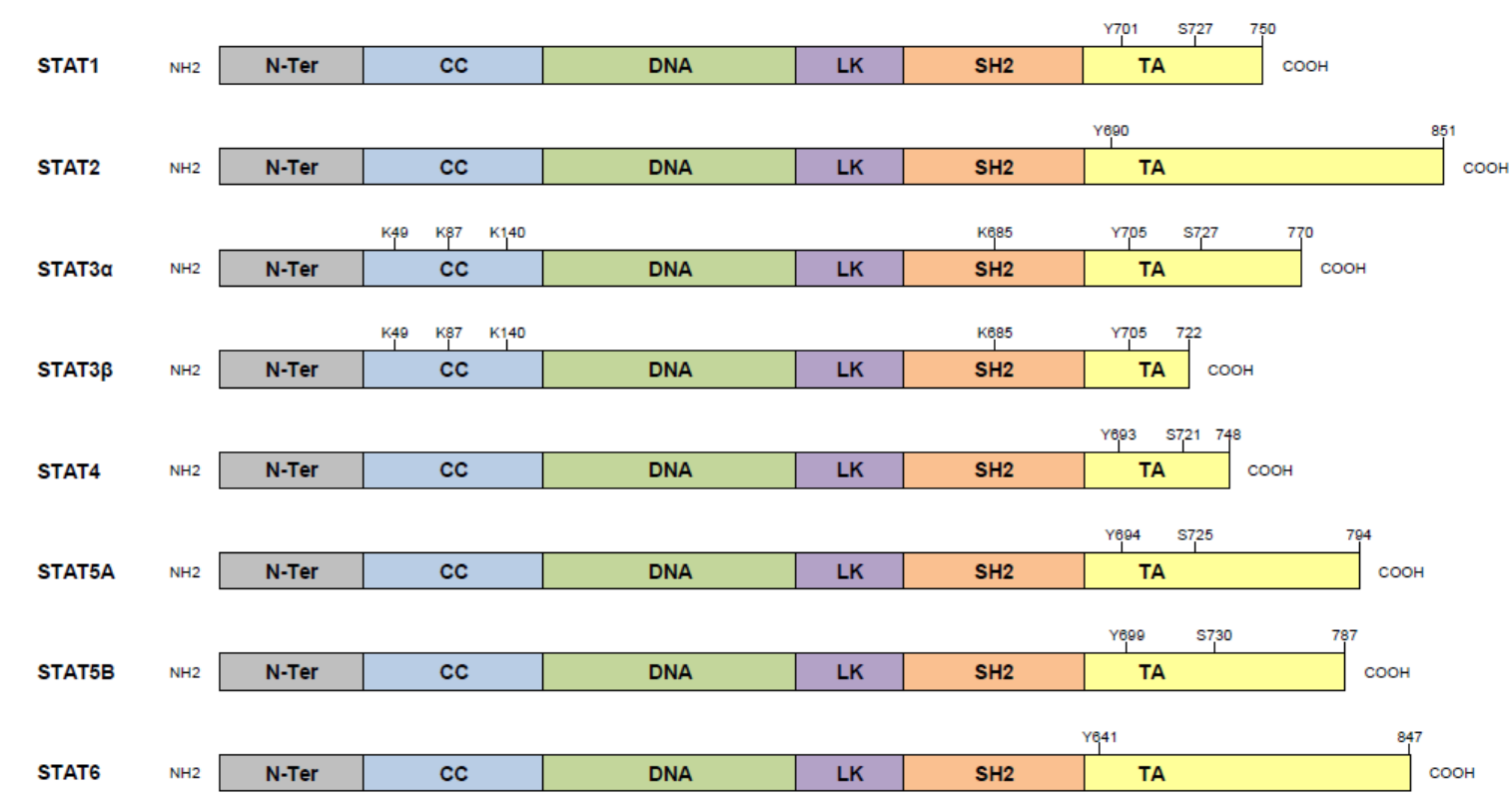


Figure 2

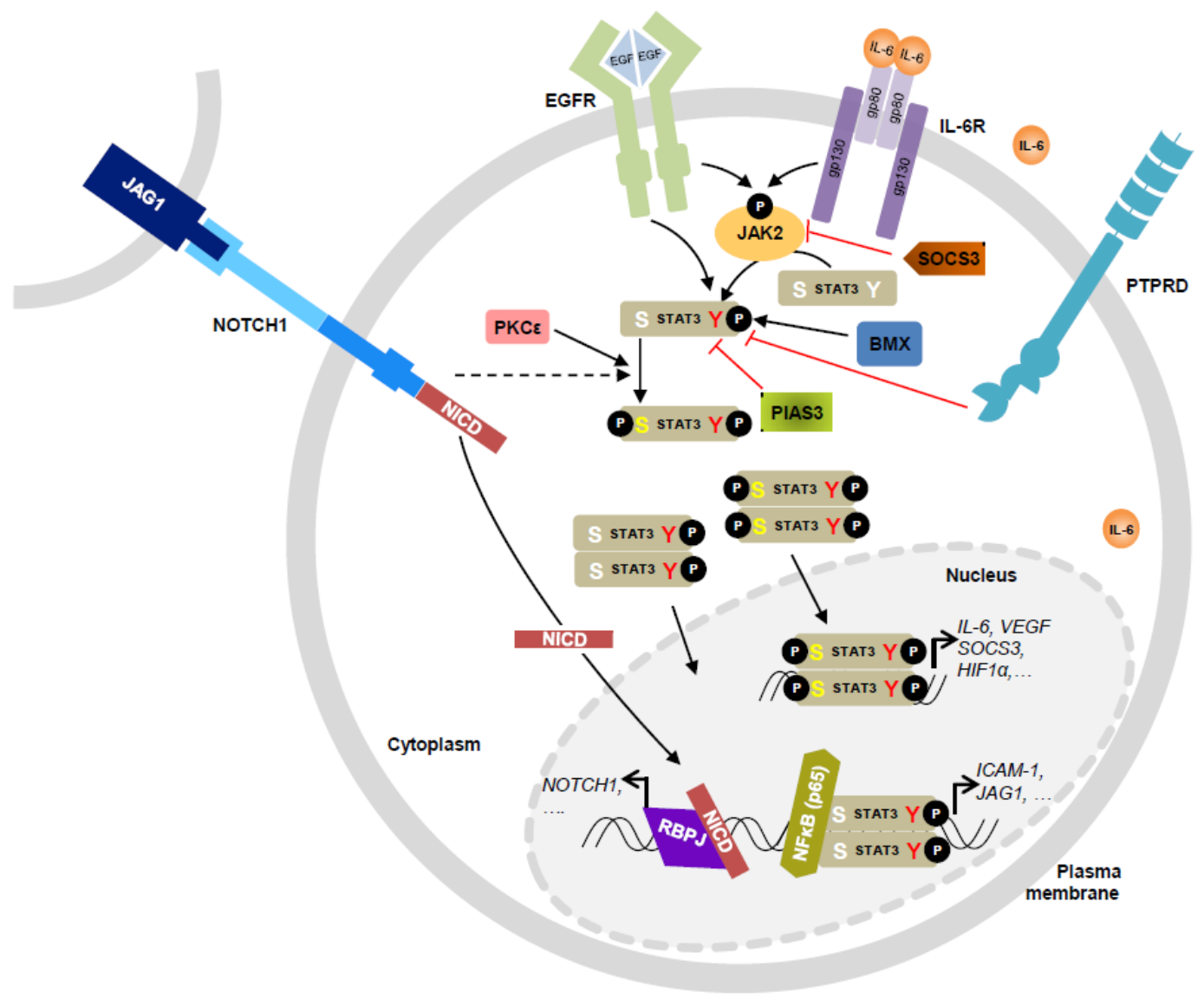

38 
Figure 3

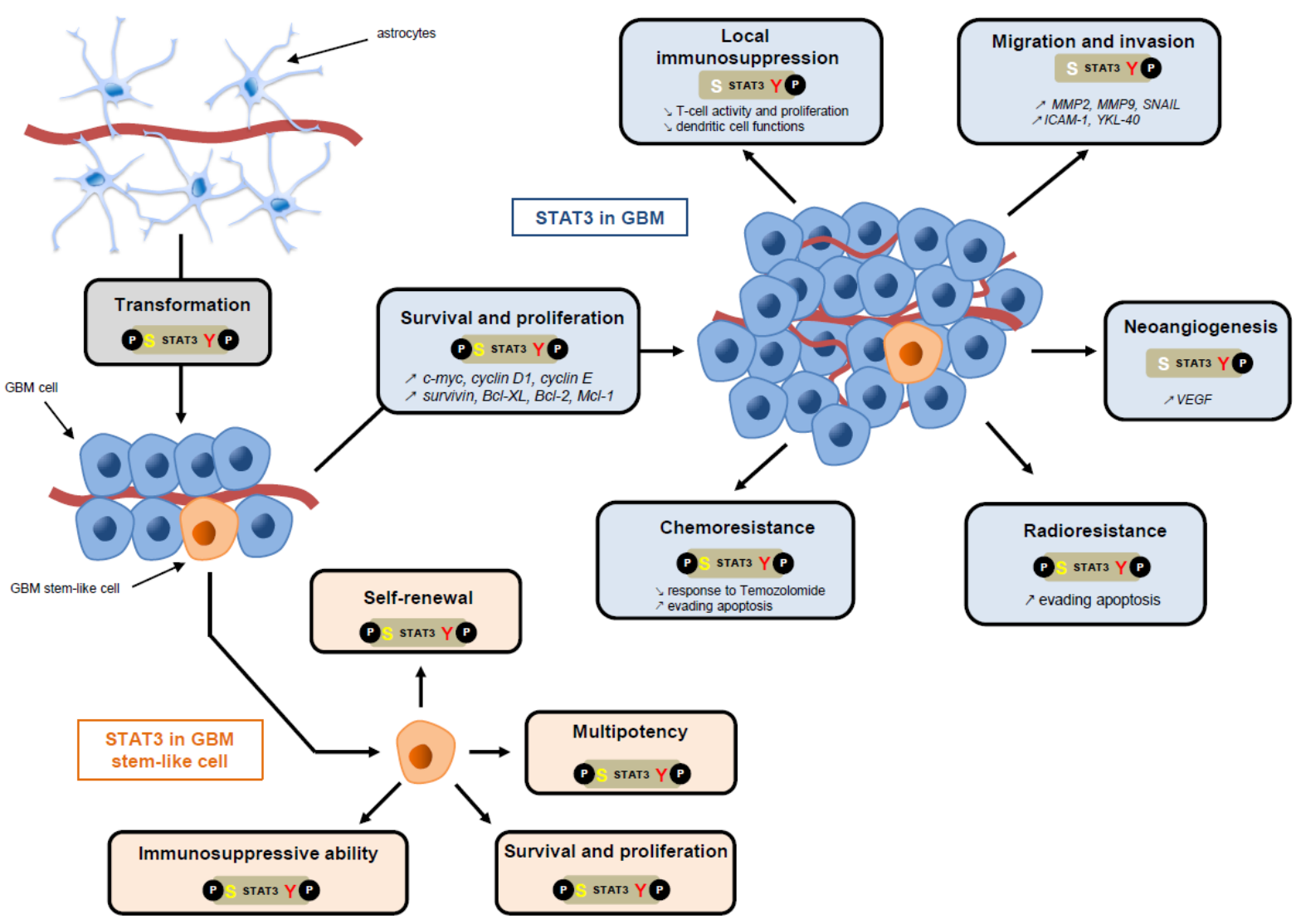

